\title{
The Value of Renewable Energy and Subsidies:
}

\section{An Investor's Perspective *}

\author{
Alexander Kronies ${ }^{\dagger}$
}

December 11, 2019

\begin{abstract}
I provide a novel theoretical approach to value wind energy investments. It allows to adjust for a number of risk parameters, including wind speeds, electricity price forecasts, discount rates, and uncertainty in subsidies. I use this approach to model wind energy investments under two different subsidy schemes in Denmark through a numerical Monte Carlo simulation. Moreover, I model wind energy investments under the assumption of a subsidy-free asset class. I compare the three systems and expose them to various sources of uncertainty through which I provide more clarity on which risk parameters matter most to wind energy investors and how the three systems compare to each other.
\end{abstract}

Keywords: Energy finance, valuation, project finance, subsidies.

JEL Classification: G10, G20, Q50, (Q48).

*I thank Carsten Sørensen, Ken L. Bechmann, Lars Christian Gaarn-Larsen, Andreas Brøgger, Stefan Hirth, Ramona Westermann, Kristian Miltersen, Mohamad Afkhami, the conference participants of the $3^{\text {rd }}$ Commodity Markets Winter Workshop 2019 at the Leibniz University of Hannover, the annual PhD Day 2018 at the Copenhagen Business School, the Commodity and Energy Markets Association (CEMA) Annual Meeting 2019 at the Tepper School of Business, as well as seminar participants at Energistyrelsen and Vestas for helpful comments and discussions. The code used for the analysis is available upon request. All mistakes are mine.

${ }^{\dagger}$ Copenhagen Business School and Pension Research Centre (PeRCent). Email: akr.fi@cbs.dk 


\section{Introduction}

This paper proposes a valuation model for wind energy projects in the Danish market. Through simple adjustments, however, an investor in another country could equally well apply it. It combines technical and financial mechanisms that are prevalent when considering wind energy investments. In particular, it consolidates the production function of turbines with an outlook in the Danish electricity price. A numerical example is applied to calculate and compare the value of two different subsidy systems in Denmark. Also, I value wind energy investment under no additional subsidy compensation. Finally, I vary a number of parameters in the model and introduce uncertainty in subsidy systems to exhibit investors' exposure to different sources of risk.

Not only in Denmark but across the world the renewable energy sector picks up momentum. Environmental impacts of traditional energy sources stress the importance of rethinking how we produce energy and how we could transform to more sustainability the energy industry. International agreements as, for example, the Kyoto Protocol $^{1}$ are one way to make countries more aware of their environmental footprint and demand commitments for changes. However, there is no universal framework in how to pursue and achieve the goal of cleaner energy production and member countries of these agreements are mostly left alone to adapt to agreements. Nonetheless, there is an international understanding that, in particular, the promotion of more renewable energy sources represents one vital pillar of that journey.

Denmark has committed itself to produce $50 \%$ of all electricity through renewable sources by $2030 .^{2}$ Wind energy in particular has been a vital contributor to Danish energy production from an early stage, see Figure 10. Today, Denmark is considered a pioneer in the industry. Every day, Denmark produces a significant share of its electricity needs through wind energy and even sells some of it to neighboring countries. Next to other factors as favorable environmental conditions or technical expertise, the excellent standing of the wind energy industry in Denmark today is due to generous subsidy systems, accelerating investment and making it competitive with traditional sources.

This study adds to a better understanding of how we can assess wind energy investments from a risk and opportunity perspective. It develops a model with which investors can value wind energy

\footnotetext{
${ }^{1}$ For more information, please see United Nations Climate Change.

${ }^{2}$ For more information, please see State of Green.
} 
investments under the variation of various risk parameters. This is possible as the study precisely takes into account the operating principals of wind energy and combines them with classical financial methods.

First, I review the production function of wind turbines from a rather technical perspective. I further examine how wind speeds are modeled and thereby develop an understanding of how we can think of energy production through wind.

Secondly, I look at the Danish electricity market over the last four years and propose a way how investors could think of spot prices in the future. By definition, electricity depicts the (only) commodity that wind energy producers sell and thereby represents the only source of income for investors when neglecting additional subsidies. In particular, I review the Nordpool System (SYS) spot market price for electricity from 2014 until the end of 2017, denoted in Euro (Figure 2). I use historical data to forecast electricity prices over a time horizon of 25 years, combining methods from Lucia and Schwartz (2002) and Seifert and Uhrig-Homburg (2007). My forecast for the Danish electricity price incorporates a seasonal pattern over different times of the year and stochastic part, which adds mean-reversion and a jump component to the time series simulation. Though this forecast intends to primarily serve the valuation model of the paper, it also sheds light on electricity price patterns in the market.

In another step, I review subsidies in the Danish renewable energy industry for two reasons. First, I aim to value wind energy investments as whole, meaning that subsidies as part of the cash flows must be considered. Secondly, the paper values their share as part of the investment as a whole. I examine subsidies in wind energy under no uncertainty as well as under uncertainty by considering future subsidy cuts. All of the above provide a grasp on how regulatory changes may impact investors' renewable energy assets. Please note that even though many professionals might refer to subsidies as feed-in-tariffs, I stick to the term of subsidies throughout the study.

The two subsidy system regarded in this study are what I call the old and new subsidy system. Up until 20.02.2018, onshore wind energy investors were entitled to generous subsidy compensation that guaranteed them $25 \varnothing \mathrm{re} / \mathrm{kWh}(€ 33.5 / \mathrm{MWh})$ for the first 22.000 full load hours on top of $2.3 \varnothing \mathrm{re} / \mathrm{kWh}(€ 3.1 / \mathrm{MWh})$ balancing costs for electricity over the lifetime of a project. This is what I call the old system.

After this old subsidy scheme ran out, Denmark successfully implemented a new tender-based 
system. The procedure is such that investors intending to develop a new wind farm can place a bid at a yearly auction for receiving a fixed subsidy on top of the market price of electricity. The maximum bid is capped at $13 \varnothing \mathrm{re} / \mathrm{kWh}$. The budget is constrained to $254 \mathrm{mDKK}(34 \mathrm{~m} €)$ in 2018 and $579 \mathrm{mDKK}(78 \mathrm{~m} €)$ in 2019 . If accepted, the additional compensation is granted for a time-horizon of 20 years. One auction each takes place in 2018 and 2019, in which the lowest bids are accepted until the given budgets run out. ${ }^{3}$ This is referred to as the new subsidy system.

Moreover, I consider wind energy investments under no additional compensation through subsidies, allowing me to compare and evaluate the two systems against the assumption of a subsidy-free investment opportunity. The model proposed by this paper could, however, implement any other subsidy system and value their share as part of the investment.

Lastly, I review the cost structure of wind energy investments. This includes maintenance costs over time as well as initial capital expenditures. As costs are not examined as a source of uncertainty in this framework, I take them as given and do not consider unforeseen additional costs or other expenditures (e.g. repair costs).

In another step, I combine all pillars, constructing a model to forecast future cash flows from wind energy investments. I apply this model to a numerical example and put the subsidy systems to the test. In particular, I assume an average-sized wind turbine and run a Monte Carlo simulation predicting different outcomes of the investment opportunity. I discount the simulated cash flows to generate present value estimates and compare them to the initial capital expenditures of the project. Furthermore, I vary a selection of parameters to examine the investment's exposure to its unique risk sources. Next to a variation in wind speeds (production), electricity price forecasts, and discount rates, this includes the consideration of subsidies under uncertainty. Furthermore, I determine an equilibrium bid under the new subsidy system under which it is equally profitable as the old system.

The remainder of this paper is structured as follows. A literature review looks at the old and new subsidy system and exhibits through which channels investors generate income. The methodology sets up the theoretical framework of the income model and reflects on the production function of wind turbines and the Danish electricity price. A Monte Carlo simulation fills the theoretical model with a numerical example, which then leads to the results in the section thereafter. An outlook on

\footnotetext{
${ }^{3}$ For more information, please see WindPowerMonthly and Energistyrelsen.
} 
future research and implications for the Danish wind energy sector conclude the paper.

\section{$1.1 \quad$ Literature Review}

The paper's primary objective is two-folded. On the one hand, it proposes an approach to more realistically forecast future cash flows of wind energy investments. On the other hand, it investigates the meaning of subsidies for wind energy investments' profitability. Next to the changes in subsidy systems, the study carefully takes into account uncertainty in future income streams, based mainly on suggestions by Dixit et al. (1994). The model allows to easily adjust for changes in a variety of parameters and thereby determine the effects on wind energy investments. This first section lays the groundwork for the methodology. After outlining the basic technical principles of wind energy production, I review all sources relevant for generated income by wind turbines.

Put bluntly, wind turbines produce electricity when the wind blows and stimulates them. In principle, the more wind blows, the higher the degree of stimulation and the more is produced. At some wind speed, the turbine reaches a maximum capacity level and eventually is turned off, when wind speeds exceed the cut-off level. Estimating, how much is produced precisely at which wind speed is a challenge in itself and relies on numerous factors, some of which include air density, blade lengths, etc. For this study, an approximate but academically accepted and sufficient approach constitutes different levels of energy production at every possible wind speed (Wan et al., 2010). The production units used for this study are megawatt-hours (MWh), where 1MWh equals 1000kWh. The only source of uncertainty in production is wind speeds. Related literature suggests that wind speeds are most precisely characterized by a Weibull distribution (Gryning et al., 2016). Figure 11 in Appendix B exhibits a typical probability density function of a Weibull distribution and how it is applied to model wind speeds.

The produced electricity is sold to the current market price. As electricity is the only commodity produced and sold, the market price level is vitally important for investors. Typically, prices fluctuate heavily and according to the demand in different times of the day, weekdays and seasons, see Villaplana Conde et al. (2002) or Escribano et al. (2011). High (low) market prices lead to an increase (decrease) in cash flows, making renewable energy investments highly dependent on the market price level. Wind or other renewable energy sources produce electricity whenever the environmental conditions allow them to do so, and due to the impossibility of storing, sell the 
commodity immediately, making investments even more dependent on its market price. Not only short-term fluctuations but also the long-term projections of its price level add uncertainty to renewable energy investments. Due to high front-up investment costs, investors are financially burdened if long-term electricity price levels fall significantly short of their projection, and because of high degrees of illiquidity, they might be stuck with their asset (Barcelona, 2017). Forecasting and in particular developing an understanding of long-term trends in electricity prices has challenged many academics not only in Nordic countries but across the world (Lucia and Schwartz, 2002). I apply an approach by Lucia and Schwartz (2002) and Seifert and Uhrig-Homburg (2007) and utilize historical Danish electricity spot prices to forecast prices as part of the model. I additionally incorporate previous findings of potential causalities between electricity prices and production as part of the electricity price forecasts, e.g. Cutler et al. (2011), Rathmann (2007) or Würzburg et al. (2013). This means that the level of production has an impact on the price level, so that a independent view on production and electricity prices does not reflect reality.

As outlined in the introduction, the renewable energy industry has picked up momentum not necessarily because of promises to more sustainability in themselves but rather due to favorable subsidy schemes. This holds especially true for Denmark, where we witnessed significant increases in renewable energy throughout the last decades, see Figure 10 in Appendix A. Due to the subsidies' significance in the renewable energy industry up to this day, they are a focal point of this paper (Barcelona, 2017). On the one hand, the implementation of subsidy support systems typically promotes and advances private investment. On the other hand, they create an additional source of uncertainty due to potential regime shifts in the future. Investors are concerned that a favorable investment today might turn into an unfavorable one tomorrow because subsidy systems change. Sudden adjustments in regulation, perhaps even retroactively, lead to jumps in asset values and profitability parameters. In 2011, Spain, for example, cut its feed-in-tariffs for solar photovoltaic energy, provoking substantial losses for investors. ${ }^{4}$

Until 20.02.2018 Danish wind energy producers received fixed premiums on top of the market price as subsidies. ${ }^{5}$ Operators were compensated with an additional $25 \varnothing \mathrm{re} / \mathrm{kWh}(€ 33.5 / \mathrm{MWh})$ for the first 22.000 full load hours on top of $2.3 \varnothing \mathrm{re} / \mathrm{kWh}(€ 3.1 / \mathrm{MWh})$ balancing costs for electricity

\footnotetext{
${ }^{4}$ Renewable energy: Subsidy cuts cause crisis of confidence, Financial Times (2011).

${ }^{5}$ On-shore plants commissioned between 01.01.2014 and 20.02.2018 received fixed premiums: Legal Sources on Renewable Energy.
} 
over the lifetime of the project and regardless of accumulated full load hours. ${ }^{6}$ Full load hours refer to the electricity output of a wind turbine under maximum capacity. Typically, the first 22.000 full load hours are exhausted after a time horizon of 5 to 7 years into the project. Similar support systems are active throughout the world in various forms and magnitudes.

On 20.02.2018 Denmark abolished this subsidy scheme and instead implemented a new tenderbased and technology neutral system. Commissioned projects between 01.01.2014 and 20.02.2018 stay under the old subsidy system and newly commissioned projects will be subject to the new system. After initial regulatory difficulties, Denmark has committed itself to this new model in agreement with the European Union. For 2018 and 2019, the Danish state provides funds that are to be exhausted for renewable energy projects. ${ }^{7}$ The process is such that investors submit a bid for each eligible project at an auction to receive subsidies. The tender-based system is technology neutral, so that any type of renewable energy project is invited to place bids. Denmark thereby imposes competition not only within individual technologies but across the entire scope of renewables. The auction caps the maximum bid at $13 \varnothing \mathrm{re} / \mathrm{kWh}(€ 17.4 / \mathrm{MWh})$ and it accepts the lowest placing bids first until the fund for the given year is exhausted. If granted, investors receive additional compensation as high as their bid for a time horizon of 20 years and regardless of the number of production hours. Because there is now a time rather than a productivity constraint, long-lasting and highly productive projects especially encouraged. The additional $2.3 \varnothing \mathrm{re} / \mathrm{kWh}(€ 3.1 / \mathrm{MWh})$ in balancing costs, provided under the old system, are omitted.

Developing and operating wind turbines incorporates costs. This includes cost elements as maintenance, insurance, land lease, own production, etc. For simplicity, they are pooled and referred to as operational expenditures later in the paper. Amirat et al. (2009) point out that operational expenditures in wind energy are not trivial. Furthermore, there is also a large difference between on-shore and off-shore wind parks. Throughout this paper, however, I built on the simplified assumption of constant operating costs mainly because the objective of this paper revolves around other and perhaps more relevant parameters.

Summing up over income and costs, cash flows from wind energy projects feed on four components. This include production, electricity spot prices, subsidies, and costs. An investor can think

\footnotetext{
${ }^{6}$ Based on the law under the Promotion of Renewable Energy Act.

${ }^{7}$ For 2018 and 2019 funds of $250 \mathrm{mDKK}$ and $579 \mathrm{mDKK}$ are provided for newly commissioned projects: Energistyrelsen.
} 
of it as

$$
\text { Income }=\text { Production } *(\text { Electricity Price }+ \text { Subsidies })-\text { Operational Expenditures } .
$$

The methodology and analysis outlined in the subsequent chapters builds on this equation in accordance with the review of its individual items. In a nutshell, it finds ways to think of each of these single components in a realistic way first, and finally puts them back together to forecast future cash flows under differing assumptions and subsidy systems.

The paper attempts to prove three implicit hypotheses. First, I assume that it is the production, the electricity price, and subsidies that predominantly determine the favorableness of wind energy investments. Uncertainty in these drivers burden investors to high degrees. Second, I start from the premise that the new Danish subsidy system is less advantageous than the old system from a valuation perspective. Even the maximum bid allowed in the newly established tender process is unlikely to outperform the wind energy investments under the now abolished old system. Finally, I suspect that because wind energy investments are profoundly dependent on subsidy compensation, and the assumption of potential subsidy cuts throughout the investment's life-cycle will substantially hurt an investment's performance valuation.

This paper contributes to the existing literature in many ways. It develops an income model for wind energy that is not only applicable to the Danish market but for many others also as it is easy to adjust to other subsidy systems. To my knowledge, no comparable study approximates income from wind energy in a similar and hands-on manner. It allows for the variation of different parameters and can easily adjust to different geographical locations and wind turbine specifications. It thoroughly determines and applies the production function of wind turbines in combination with a forecast of the Danish electricity price. Secondly, I compare two subsidy systems in the Danish market, examine their differences from an investor's perspective, and find an equilibrium in which the two systems are equally favorable. Additionally, the study investigates the case of no subsidies. Lastly, the variation of different parameters adds to a clearer picture of uncertainty in wind energy investments and how investors can think of risk and opportunity in this unique asset class. 


\section{Methodology}

This chapter outlines the approach to simulate income $\left(I_{t}\right)$ of wind turbines under risk and uncertainty, which it then applies to forecast cash flows for a hypothetical wind energy investment in Denmark under different scenarios. The results provide clarity on the magnitude of chosen risk parameters as well as the value and comparison between subsidy schemes. In short, I predict future cash flows based on the four components of equation (1). These include production $M W h_{t}$, the electricity price $P_{t}$, subsidies $S_{t}^{\text {Old }}$ and $S_{t}^{N e w}$, respectively, as well as operational costs $C_{t}$, all at time $t$, where $\Delta t$ represents daily increment counts. Defining these four components one by one allows to take into account uncertainty through the variation of single risk parameters. Sensitivity analyses of these relevant risk parameters add to understanding risk and opportunity in the asset class.

The remainder of this chapter is organized as follows. First, I derive the production function of wind turbines. Second, the study examines the electricity spot price from 2014 until 2017 and, based on Lucia and Schwartz (2002) and Seifert and Uhrig-Homburg (2007) reviews and later applies a forecasting method. Third, I quantitatively define the two different subsidy systems and necessary assumptions as processes with and without incorporating uncertainty. Moreover, I review the maintenance and operating costs of wind energy production. Finally, the study puts together all four parts, defines a hypothetical investment in a wind turbine, and simulates income in the spirit of equation (1) over a time horizon of 25 years. The combination and partial substitution of all components allow to review wind energy investments from a risk and return relationship, and also to compare and distinguish between different subsidy schemes.

\subsection{Wind Energy Production}

The right estimation of wind energy production is a highly complex task, and one with which engineers have spent years to approximate outputs as precise as possible. ${ }^{8}$ As for all wind energy projects, the approximate output of $M W h_{t}$ follows the production function of Figure 1, expressed in equation (2). The parameters $\rho, A, \bar{V}$, and $C_{p}$ define the air density, rotor area, average wind speed and the power coefficient (for more information, see Yu and Tuzuner, 2008). The production

\footnotetext{
${ }^{8}$ Many Danish producers rely on estimates given by calculations by the Danish Wind Industry Association.
} 
Figure 1: Power generation.

This graphs illustrates equation (2), neglecting $h$ to determine energy output. Wind, $V$, is measured in $\mathrm{m} / \mathrm{s}$. $V_{\min }$ and $V_{\max }$ are commonly referred to as the cut-in and cut-out speed, respectively. $V_{r}$ depicts the rated wind speed, where the turbine reaches its maximum capacity and produces $M W_{\max }$.

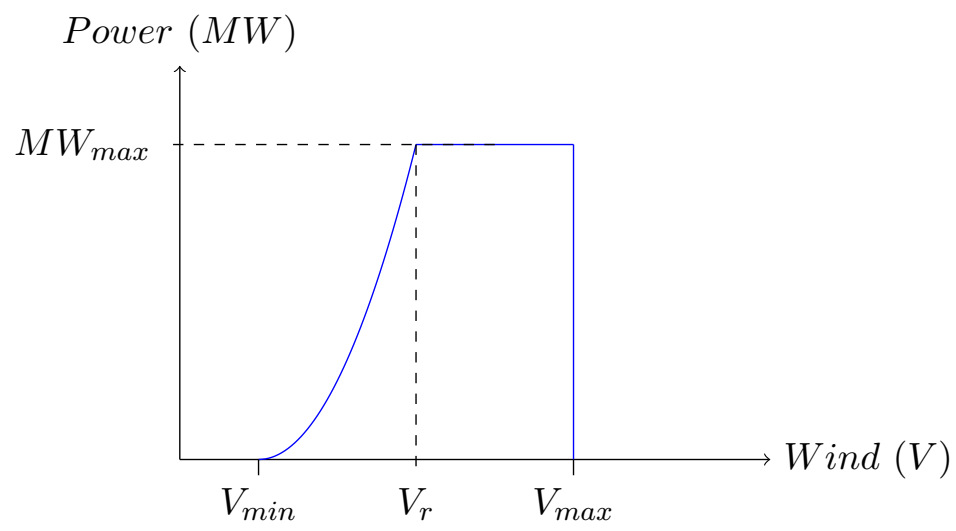

output of wind energy can then approximately be estimated as follows:

$$
M W h_{t}=f\left(\bar{V}_{t}\right)= \begin{cases}0 & \text { if } \bar{V}_{t}<V_{\text {min }} \\ \min \left[\frac{1}{2} \rho A \bar{V}_{t}^{3} C_{p} 10^{-6} ; M W_{\max }\right] * h & \text { if } V_{\min } \leq \bar{V}_{t} \leq V_{\max } \\ 0 & \text { if } \bar{V}_{t}>V_{\max }\end{cases}
$$

Electricity production starts at a given cut-in speed $\bar{V}_{\min }$ and stops at the cut-out speed $\bar{V}_{\max }$, meaning that before $\bar{V}_{\text {min }}$ and after $\bar{V}_{\max }$ there is no output. In between, production first increases steeply until it reaches a maximum productivity level of $M W_{\max }$, see Figure 1 . The parameter $h$ depicts the number of hours the wind turbine operates a day. ${ }^{9}$

As mentioned above, the power output per day, can be expressed as the function of wind $f\left(\bar{V}_{t}\right)$. $\bar{V}_{t}$ is the only random variable and changes at time $t$, following a Weibull distribution. The Weibull distribution calls for an estimation of the scale and shape parameters $A$ and $k$, see Appendix B. I apply the methodology of (Johnson et al., 2005) to simulate average daily wind speeds. Gryning et al. (2016) note that Weibull distributions are typically used for the estimation of hourly wind speeds. In this framework, however, it serves as an estimation for average daily wind speeds.

\footnotetext{
${ }^{9}$ Please note that the power function (2) derived for this paper serves as an approximation for power outputs and is applied because of its easy implementation. The even more precise power function slightly deviates from the equation (2) and Figure 1, but due to its increased complexity and only incremental improvement is not utilized within this framework.
} 


\subsection{Electricity Price}

The most vital component of income from wind energy investments is electricity prices. I use historical data to derive parameter estimates to forecast electricity spot prices, and later apply as part of the investment valuation of a Danish wind turbine. Specifically, I obtain hourly electricity spot prices from the Nordic electricity market irrespective of capacity congestion in the individual interconnections between the areas of Denmark, Sweden and Germany (referred to as SYSTEM), see Energi Data Service.

First, I average hourly prices over each day to obtain daily prices, see Figure 2. Spot prices are highly volatile not only in the given time-series but also over longer horizons, an observation typical for other electricity markets as well. Various spikes lead to high and significant short-term price volatility. Furthermore, there are seasonal movements in the data, meaning that prices vary across different seasons of the year. This comes as no surprise assuming that households demand less (more) electricity in the summer (winter) and proves previous findings in the literature, e.g. Lucia and Schwartz (2002), Seifert and Uhrig-Homburg (2007), Villaplana (2003) or Escribano et al. (2011).

The numerical application requires to forecast electricity prices for a time horizon of 25 years. I choose a mean-reverting model with seasonality and a jump component in the spirit of Lucia and Schwartz (2002) and Seifert and Uhrig-Homburg (2007). It uses historical data to estimate the required parameters. As the estimation period is very long and regimes might change to large degrees throughout time, I must stress that this forecast merely serves as an approximation and does not attempt to confidently forecast the electricity spot price for the time horizon in question.

Lucia and Schwartz (2002) investigate historical data from the Nordic Power Exchange and note three important characteristics of electricity spot prices. First, they contain jumps that occur in times of high demand and (or) little supply. Most times however, prices quickly return so some average level quickly. Lastly, they exhibit a seasonal pattern throughout the year. As also visible in Figure 2, spot prices are typically higher (lower) in cold (warm) seasons due to a variation in demand. They note that the changes in climate in different seasons lead to shifts in the demand for heating and thereby demand for electricity.

Acknowledging these empirical facts, a process is split in two parts, a deterministic function 


\section{Figure 2: Electricity Price.}

The graphic captures daily spot prices of the Nordic electricity market irrespective of capacity congestion in the individual interconnections between the areas of Denmark, Sweden and Germany (referred to as SYSTEM). The price is denoted in EUR per MWh. Source: Energi Data Service.

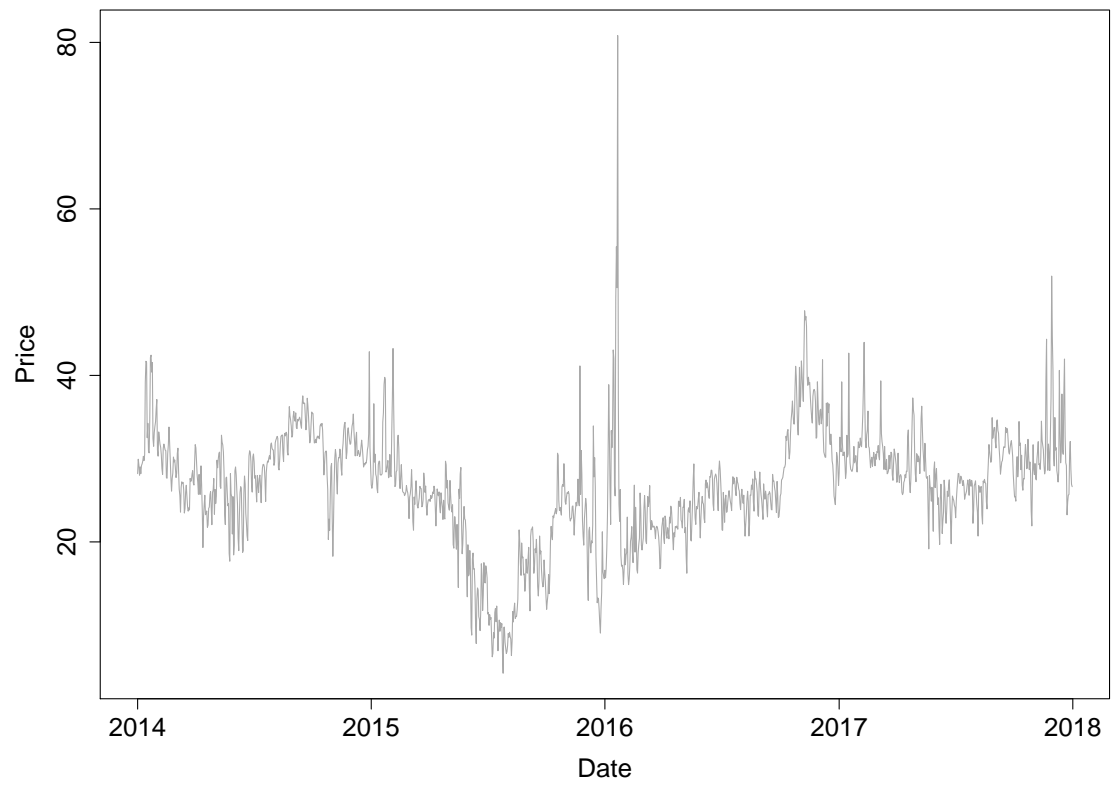

of time that captures seasonal patterns and a diffusion stochastic process that incorporates meanreversion and jumps. Following Seifert and Uhrig-Homburg (2007), the logarithm of the spot electricity price $P_{t}$ is expressed as

$$
\ln P_{t}=f(t)+X_{t}
$$

The components $f(t)$ and $X_{t}$ depict the deterministic seasonal part and the stochastic part, respectively. The seasonal component is modeled as

$$
f(t)=s_{1} \sin (2 \pi t)+s_{2} \cos (2 \pi t)+s_{3} \sin (4 \pi t)+s_{4} \cos (4 \pi t)+s_{5}+t \mu
$$

where $s_{1}, \ldots, s_{5}$ are constant parameters and $\mu$ is the drift in the seasonality estimation. Therefore, $\mu$ captures the expectation in long-run average price developments.

Finally, $X_{t}$ captures a mean-reverting Ornstein-Uhlenbeck process with jumps, analogous to Seifert and Uhrig-Homburg (2007). 


$$
d X_{t}=\left(\alpha-\kappa X_{t}\right) d t+\sigma_{X} d W_{t}^{X}+\xi_{t} d J t
$$

Here, $\alpha$ and $\kappa$ are mean-reversion parameters; $\sigma$ is the volatility, and $W_{t}$ depicts a standard Brownian motion. $J_{t}$ captures a Poisson process with a jump intensity of $\lambda_{J}$ and is normally distributed with a jump size of $\xi_{t} \sim N\left(\mu_{\xi}, \sigma_{\xi}\right)$. This model is considered not only by Seifert and Uhrig-Homburg (2007), but many others, for example, Villaplana (2003) or Escribano et al. (2011).

The procedure goes as follows. First, the deterministic seasonality part is computed through the least squares method. The seasonality part is then removed from the time series and the stochastic part is calibrated through maximum likelihood estimation. I then use the estimated parameters, found in Table 1, as the basis for forecasting electricity prices over 25 years. ${ }^{10}$ Figure 3 provides one single simulation of this forecast and exhibits estimated prices when historical data runs out. Furthermore, Appendix C discloses how the distributions of historical data look in comparison to the simulated data.

\section{Figure 3: Forecasts.}

Figure 3a exhibits the seasonality in the Nordpool System spot market log(price) from 2014 until 2018 on a daily basis. After 2014, prices are foreasted applying equation (3) and estimates from Table 1. Figure 3b reflect the exponential of the log-normal historical and forecasted prices.

(a) Seasonality in the Log Price and Forecasts.

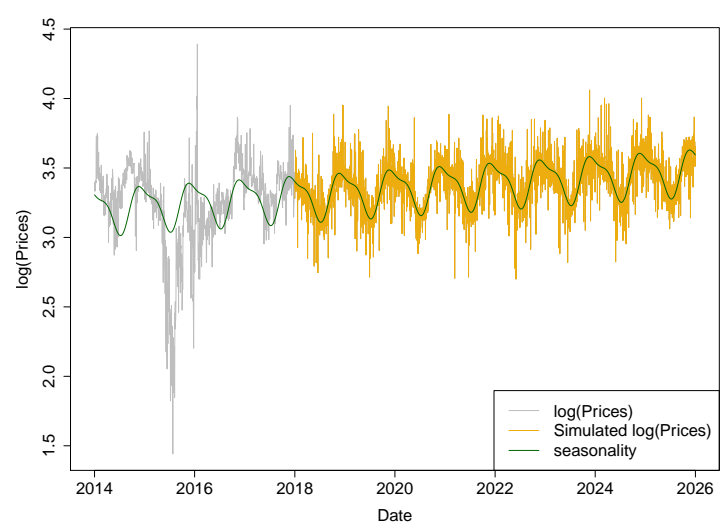

(b) Seasonality Electricity Price and Forecasts.

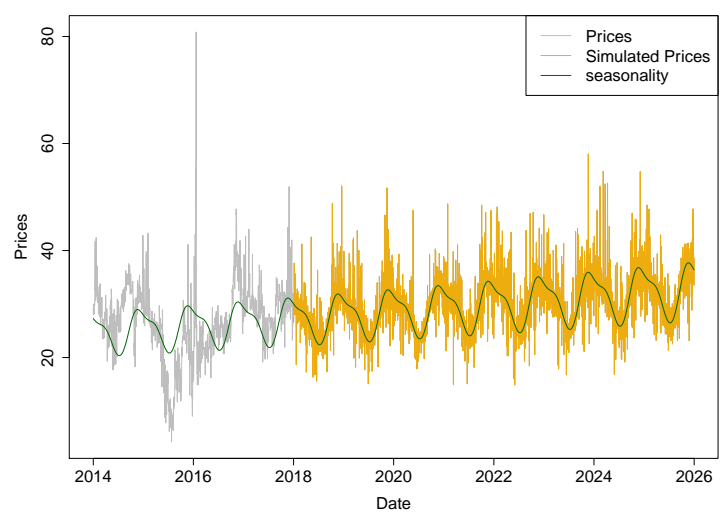

\footnotetext{
${ }^{10} \mathrm{~A}$ similar simulation, but instead based on different data and implemented in Matlab instead can be found here.
} 


\subsubsection{Price vs. Production}

A number of studies document a negative causal relationship between renewable energy production and electricity prices, e.g. Cutler et al. (2011), Rathmann (2007) or Würzburg et al. (2013). This effect is commonly referred to as the 'merit-order effect'. The argument for that finding is that increased renewable energy production shifts the supply curve to the right, resulting in a lower equilibrium price. The size and sometimes even the direction of this effect, however, is controversial (Würzburg et al., 2013).

I test this effect in the Danish market by a simple regression approach. I download data on the Danish wind energy supply from Nord Pool AS and regress the log-price of electricity against daily aggregated wind energy supply. ${ }^{11} \mathrm{I}$ define production as the total output in day $t$ over the average of the time series. Appendix D displays the results.

Though minor, I find a significant negative coefficient of production on daily electricity log-prices of approximately -0.045 . Even when controlling for lagged prices, the coefficient stays constant. Because the objective is to invent a realistic and hands-on income and valuation model, it needs to take this stylized fact into account. If instead, the negative causality would be neglected, future income estimation would be overstated. I therefor add a factor $\beta$ to equation (3), correcting for the impact of production on market prices.

$$
\ln P_{t}=f(t)+X_{t}+\beta \frac{f\left(\bar{V}_{t}\right)}{f(\bar{V})}
$$

The factor $\beta$ captures the economic effect of the daily electricity output on the price that the investor receives for his supply. Even through, this effect is minor from first sight, it impacts the total income generated by the investor. Also, in light of more renewable energy investments in the future, this causality might strengthen due to the increased volatility in supply as an effect of changing wind speeds and also the inability of energy storage.

The absolute effect is larger for high production times, and vice versa. By default, it changes the price series of electricity, however, it is not to be seen as an extended version to Seifert and Uhrig-Homburg (2007). It rather refers to what investors actually earn throughout each average day of production, adjusting for the fact that in times of higher supply prices tend to be lower.

\footnotetext{
${ }^{11}$ Data can be accessed here.
} 


\subsection{Subsidies}

Apart from the income generated through the market price of electricity, investors are compensated with an additional premium paid per $M W h$ they produce and feed into the grid, an incentive set by the government for investors to engage in renewable energy technologies and have them compete with cheaper traditional energy sources. The study considers two different subsidy systems and refers to them as an old and a new system. In addition, I also consider the case of no subsidies throughout the analysis. The old system ran out on the 20.02.2018, whereas the new system has just been put in place by the Danish authorities in alliance with the European Union and their regulatory requirements. ${ }^{12}$ Both, the old and the new system are outlined hereafter and expressed as processes to incorporate in the income model and as part of equation (1). In a second step, I consider uncertainty in subsidy compensation to examine another source of financial risk in the subsequent numerical implementation.

\subsubsection{No Uncertainty in Subsidies}

Referred to as the old subsidy compensation system, producers who commissioned projects until 20.02.2018 are compensated with $25 \varnothing \mathrm{re} / \mathrm{kWh}$ (€33.5/MWh), represented by $G$, for 22.000 full load hours on top of $2.3 \varnothing \mathrm{re} / \mathrm{kWh}(€ 3.1 / \mathrm{MWh})$, exhibited in $B$, balancing costs for electricity over entire the lifetime of the project.

$$
S_{t+1}^{\text {Old }}= \begin{cases}G+B & \text { if } \sum_{j=1}^{t+1} f\left(\bar{V}_{j}\right) \leq 22.000 h * M W_{\max } \\ B & \text { if } \sum_{j=1}^{t+1} f\left(\bar{V}_{j}\right)>22.000 h * M W_{\max }\end{cases}
$$

Note that, here, there is no uncertainty in the subsidy payouts in this definition. Investors assume that they will be granted the full subsidy stream throughout their eligibility, see Figure 4.

The new subsidy system is that of a tender. Investors can place bids on receiving subsidies per $M W h$ at yearly auctions. The lowest bids are granted to the investors until funds for each tender are exhausted. The bids must not exceed $13 \varnothing \mathrm{re} / \mathrm{kWh}(€ 17.4 / \mathrm{MWh})$. If granted the tender bid, the subsidy premium is paid on top of the market price over a time horizon of 20 years $(t=20 * 365=7300$ days $)$.

\footnotetext{
${ }^{12}$ See WindPowerMonthly.
} 


\section{Figure 4: Subsidies under no Uncertainty.}

Figure 4a depicts the old subsidy scheme in which investors are paid €33.5/MWh until they have produced 22.000 full-load hours. It drops to $€ 0 / \mathrm{MWh}$ after, which is typically the case 5-7 years into the project. Figure $4 \mathrm{~b}$ exhibits the new subsidy tender system, under which investors place bids on the subsidy compensation they would like to receive for each MWh. The bids must not exceed $€ 17.4 / \mathrm{MWh}$ and are granted for a time horizon of 20 years. The lowest bids are accepted until the given budget runs out.

(a) The old Subsidy System.

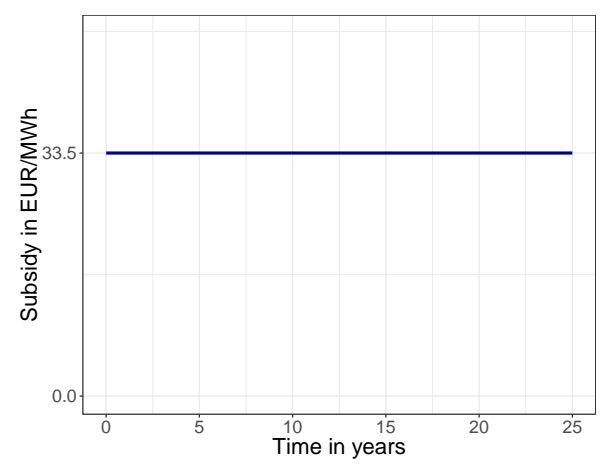

(b) The new Tender-based System.

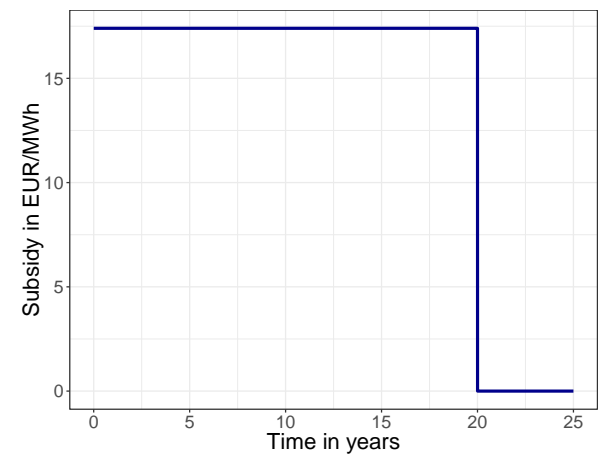

$$
S_{t+1}^{N e w}= \begin{cases}S^{N e w} & \text { if } t \leq 7300 \\ 0 & \text { if } t>7300\end{cases}
$$

Formula (8) expresses the bid that investors place as $S^{\text {New }}$. As in the old subsidy scheme, investors assume no uncertainty in this framework. They are entitled to their bid, if granted, over the project's first 20 years and assume them to be distributed with certainty, see Figure 4.

\subsubsection{Uncertainty in Subsidy}

In this section, I add uncertainty in the subsidy compensation for investors for further sensitivity analyses. I assume that it might occur over the project's lifetime that decision makers impose subsidy cuts, affecting the expected cash flows from the investment and its risk exposure. In detail, I redefine $S^{\text {Old }}$ and $S^{\text {New }}$ as the new processes that incorporate a risk parameter called $\lambda$.

In particular, the old subsidy scheme as in equation (7) changes in a way that $G_{t}$ is redefined to be uncertain in the future.

$$
S_{t+1}^{\text {Old }}= \begin{cases}G_{t}+B & \text { if } \sum_{j=1}^{t+1} f\left(\bar{V}_{j}\right) \leq 22.000 h * M W_{\text {max }} \\ B & \text { if } \sum_{j=1}^{t+1} f\left(\bar{V}_{j}\right)>22.000 h * M W_{\text {max }}\end{cases}
$$


It is assumed that investors predict future cuts in these subsidies, meaning that the state will not keep its promise to compensate them as agreed. The variable $G_{t}$, under the new assumptions, follows a jump process of

$$
G_{t+1}=\max \left[G_{t}-\tilde{\varepsilon}_{t}\left(N_{t+1}-N_{t}\right) ; 0\right],
$$

where $N_{t+1}$ is defined as

$$
N_{t+1}=N_{t}+ \begin{cases}1 & \text { with probability } \lambda^{\text {Old }} \Delta t \\ 0 & \text { with probability } 1-\lambda^{\text {Old }} \Delta t\end{cases}
$$

The probabilities are defined as

$$
\begin{aligned}
& \operatorname{Prob}\left(N_{t+1}=N_{t}+1\right)=\operatorname{Prob}\left(z_{1 t} \leq z_{\alpha}\right)=\lambda^{\text {Old }} \Delta t \\
& \operatorname{Prob}\left(N_{t+1}=N_{t}\right)=\operatorname{Prob}\left(z_{1 t}>z_{\alpha}\right)=1-\lambda^{\text {Old }} \Delta t .
\end{aligned}
$$

The parameter of $\tilde{\varepsilon}_{t}$ exhibits the magnitude of the jump that is realized if triggered and is defined as

$$
\tilde{\varepsilon}_{t}=\left|u_{o}+u_{1} z_{2 t}\right|
$$

where $u_{0}$ depicts the constant average jump in subsidies. The parameter of $u_{1}$, another constant, is multiplied by a standard normally distributed variable of $z_{2 t}$ and thereby adds uncertainty to jump's magnitude. There is no possibility of a negative jump value in equation (14), meaning that subsidy compensations cannot increase over time. Furthermore, there is no uncertainty in the constant of $B . G_{0}$ in equation (7) equals $25 \varnothing \mathrm{re} / \mathrm{kWh}(€ 33.5 / \mathrm{MWh})$ as the old subsidy scheme's starting point.

I redefine the new subsidy compensation system and incorporate uncertainty through 


$$
S_{t+1}^{N e w}= \begin{cases}\max \left[S_{t}^{N e w}-\tilde{v}_{t}\left(M_{t+1}-M_{t}\right) ; 0\right] & \text { if } t \leq 7300 \\ 0 & \text { if } t>7300 .\end{cases}
$$

The likelihood of future cuts in the subsidy level investors were granted at the auction, is expressed similarly to equation (12) and (13).

$$
M_{t+1}=M_{t}+ \begin{cases}1 & \text { with probability } \lambda^{N e w} \Delta t \\ 0 & \text { with probability } 1-\lambda^{N e w} \Delta t\end{cases}
$$

The probabilities are defined as

$$
\begin{aligned}
& \operatorname{Prob}\left(M_{t+1}=M_{t}+1\right)=\operatorname{Prob}\left(z_{3 t} \leq z_{\alpha}\right)=\lambda^{N e w} \Delta t \\
& \operatorname{Prob}\left(M_{t+1}=M_{t}\right)=\operatorname{Prob}\left(z_{3 t}>z_{\alpha}\right)=1-\lambda^{N e w} \Delta t .
\end{aligned}
$$

I assume magnitude of the jump $\tilde{v}_{t}$ to be

$$
\tilde{v}_{t}=\left|q_{o}+q_{1} z_{4 t}\right|
$$

where $q_{0}$ depicts the constant average jump under the new subsidy system and $q_{1}$ adds uncertainty to jump's magnitude by being multiplied with the standard normally distributed variable of $z_{4 t}$. As a starting point, $S_{0}^{N e w}$ is defined as $€ 17.4 / \mathrm{MWh}$, the maximum bid in the new tender-based system.

The variables of $z_{1 t}, \ldots, z_{4 t}$ are standard normally distributed random variables of $z_{i t} \sim N(0,1)$. Furthermore, $\Delta t$ equals $\frac{1}{365}$, so that $\lambda_{t}^{\text {Old }}$ and $\lambda_{t}^{\text {New }}$ are denoted on a yearly basis.

Figure 5 displays what subsidy cuts could look like in the model. Investors yield lower income in the future if subsidies are cut, lowering the present value of their investment. 
Figure 5: Subsidies under Uncertainty.

Both graphs represent sample paths of subsidy compensation streams under uncertainty of $\lambda^{\text {Old }}$ and $\lambda^{\text {New }}$, respectively, at 10\%. in Figure 5a investors investors are compensated under the old subsidy system with $€ 33.5 / \mathrm{MWh}$ at time $t=0$. Thereafter, $S_{t}^{\text {Old }}$ depends on how subsidies develop under uncertainty. Investors are then compensated with $S_{t}^{\text {Old }}$ at each instance $t$ until they have produced 22.000 full-load hours. It drops to $€ 0 / \mathrm{MWh}$ thereafter, which is typically the case 5-7 years into the project. Figure $5 \mathrm{~b}$ exhibits the new tender-based subsidy compensation scheme, under which investors place bids on the subsidy compensation they want to receive for each MWh. The bids must not exceed $€ 17.4 / \mathrm{MWh}$ and are granted for a time horizon of 20 years. This scenario assumes investors are compensated with $€ 17.4 / \mathrm{MWh}$ at $t=0$ but are exposed to subsidy cuts thereafter.

(a) The old Subsidy System.

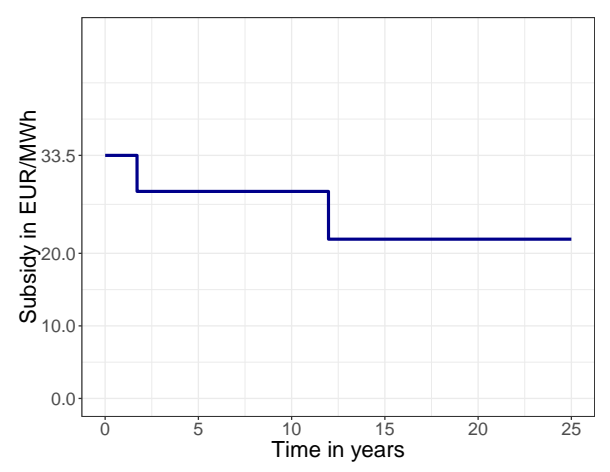

(b) The new Tender-based System.

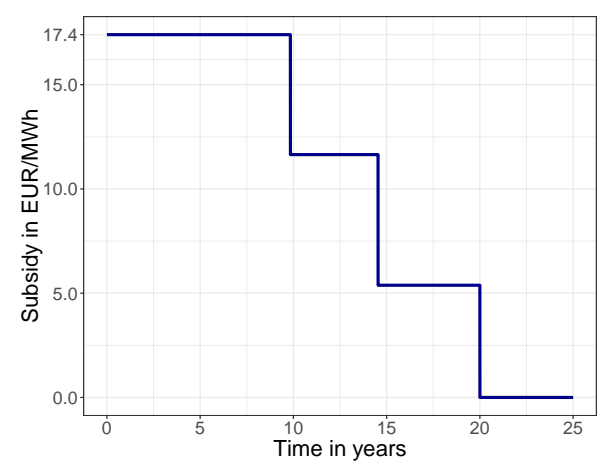

\subsection{Operating Costs}

Finally, I assume no uncertainty in the operating costs. I project yearly total costs for operation and maintenance and divide them among the total days of each year.

$$
C_{t}=C_{\text {yearly }} \Delta t
$$

Next to these continuous and systematic operating expenditures, operators might face unbudgeted costs over the lifetime of a project, such as repairs or the exchange of broken equipment. For simplicity, such unplanned events are not taken into account as the focus of this study revolves around the comparison of different subsidy schemes and other risk parameters.

\subsection{Income and Present Value Estimation}

The previous sub-chapter reviewed on all components that add to the income generated through wind energy investments. These include production, electricity prices, subsidies and costs. The examination's objective is to put these components together in a universal framework to be able to model wind energy investments under varying assumptions and to compare and value differ- 
ent subsidy schemes. I define a hypothetical wind energy investment, simulate income from the investment, discount the resulting cash flows, and add them up to present values.

Specifically, income at time $t$ and based on equation (1), follows

$$
I_{t}=M W h_{t} *\left(P_{t}+S_{t}\right)-C_{t}, t=1,2, \ldots, T
$$

Using this equation computes income for each day $t$. I consider a risk-adjusted discount rate of $r$ over each time instance $t$ and determine the present value of the investment.

$$
P V=\sum_{t=1}^{T} \frac{I_{t}}{(1+r)^{t \Delta t}}
$$

The ratio of $P V / C A P E X$ will then determine if the investment can be seen as favorable. If $P V / C A P E X>1$, investors will see the investment opportunity as profitable, and vice versa (Bodie et al., 2009). The numerical simulation discloses the present value estimation of the proposed income model. A sensitivity analysis will further expose what changes in selected parameters, for instance the probability of subsidy cuts, will do to investment opportunities.

\section{Simulation}

The valuation model outlined in the previous chapter calls for a numerical application under different scenarios and uncertainty assumptions. The results value wind energy investments, their exposure to asset-specific risk and subsidy compensation. Specifically, I apply a Monte Carlo simulation to draw outcomes for the ratio of PV/CAPEX. First, I run a base case, which computes the ratio distribution under one explicit numerical definition of variables. Secondly, I vary the wind speed scale parameter $A$, the drift in the electricity price $\mu$, and the discount rate $r$. Moreover, I determine the equilibrium bid in the new subsidy system, so that it is equally favorable as the old system. Finally, I add uncertainty to future subsidy payments by imposing default probability in subsidy distributions cuts over time. 


\subsection{The Base Case}

The previous chapter builds a cash flow and valuation model for wind energy investments, which this and the next chapter put to the test. The Monte Carlo simulation considers a single wind turbine. ${ }^{13}$ I gradually define the model's input parameters to value the investment under a plethora of variations.

First, the production function in equation (2) calls for a precise definition of a wind turbine. I assume it to have blade lengths $l$ of 50 meters and is subject to air density $\rho$ of $1.28 \mathrm{~kg} / \mathrm{m}^{3}$. Moreover, it has a power coefficient $C_{p}$ of 0.4 , a maximum capacity of $3.5 \mathrm{MW}$, a cut-in wind speed $V_{\min }$ of $3 \mathrm{~m} / \mathrm{s}$ and a cut-out speed $V_{\max }$ of $18 \mathrm{~m} / \mathrm{s}$. The wind turbine operates 24 hours a day. The wind speed scale and shape parameters $A$ and $k$ are 9 and 2.5, respectively. Wind energy investors would consider these wind speeds as very favorable. Having defined the wind turbine, modeling wind speeds through a Weibull distribution and utilizing the power function in equation (2), one can draw random power estimates, measured by MWh.

Secondly, and based on historical data from 2014 until 2017, I calculate the relevant parameters to apply equation (3) to forecast electricity prices over a time horizon of 25 years. First, I compute the seasonal parameters for equation (4) through the least squared method, providing an estimation for $s_{1}, \ldots, s_{5}$ and $\mu$. Thereafter, the estimation removes the seasonality part from the log-normalized time series and uses the output to calibrate the stochastic part via a maximum likelihood estimation, providing estimates for $\alpha, \kappa, \sigma_{X}, \sigma_{X}, X_{0}, \mu_{J}, \sigma_{J}$, and $\lambda_{J}$. Utilizing these parameters allows me to run a electricity price simulation over any given time horizon and time instances. Because the valuation model forecasts income on a daily basis, $d t$ equals $\frac{1}{365}$. Figure 3 exhibits a sample draw for the electricity spot price forecast. Even though I only need an estimation for electricity over 25 years regardless of the investment's vintage, one could think of letting the simulation start in 2018 and having it run until the end of $2042 .{ }^{14}$

In accordance to the subsidy system until 20.02.2018, the subsidy parameters under the old system are $G=€ 33.5 / \mathrm{MWh}$ and $B=€ 3.1 / \mathrm{MWh}$. The new tender-based system allows bids up to $13 ø \mathrm{re} / \mathrm{kWh}(€ 17.4 / \mathrm{MWh})$ and distributes payouts over the first 20 years of the project.

\footnotetext{
${ }^{13}$ I thank my supervisor Lars Christian Gaarn-Larsen from Energi30 for sharing his technical knowledge and data suggestions to specify a realistic numerical example for this paper.

${ }^{14}$ Note that I do not account for correlation between production and electricity prices in this approach.
} 
Though it is likely that the accepted bids are lower than the maximum allowed ${ }^{15}$, I run this first simulation under $S^{\text {New }}$ equal to $€ 17.4 / \mathrm{MWh}$ as a starting point. Under the base case, I do not assume uncertainty in subsidy distributions and apply equation (7) and (8), or equivalent, apply equation (9) and (15) with $\lambda^{\text {Old }}$ and $\lambda^{\text {New }}$ at 0 . Subsequent simulations add uncertainty in future subsidy payouts, varying $\lambda^{\text {Old }}$ and $\lambda^{\text {New }}$.

Average annual costs per year $C_{\text {yearly }}$ are $€ 72,000$ or $€ 197.26$ a day, respectively. The Monte Carlo simulation predicts future daily income $\left(I_{t}\right)$ over a time horizon of 25 years, assuming that a year contains 365 days $(T=9125$ days $)$. It neglects additional days in leap-years. An apparent challenge of the simulation is the choice of the discount rate. For a start, the base case assumes it to be $7 \%(r)$. From discussions with institutional investors, this rate seems to be an unspoken threshold for entering in wind energy. A later sensitivity analysis varies this rate and examines the investment's exposure to the chosen rate.

The simulation runs 1000 times $(N)$ under each of the two subsidy systems as well as under neither, drawing present values according to (22). Lastly, the ratio of the present value over the capital expenditures (CAPEX) in $t=0$ determines the investment's profitability. A ratio larger than 1 depicts a profitable investment opportunity, and vice versa. CAPEX equals $€ 3.500 .000$ following a benchmark of $€ 1.000 .000$ in costs per MW.

The comparison of the distributions of $P V / C A P E X$ ratios under the old, new and no subsidy systems examines differences in the three regimes as well as their total value as part of the investment opportunity. Table 1 outlines all assumptions for this base case scenario.

\subsection{Varying Risk Parameters}

The base case scenario provides an attempt to value a wind energy investment as specified in Table 1. In another step, I vary three chosen risk parameters determining their influence on the investment's profitability. The procedure goes as follows. I keep the assumptions of the base case scenario fixed and only adjust one of the three risk parameters at a time. For a single variation, I obtain a distribution similar to the base case, meaning that each data point in the given range is used to simulate 1000 draws of $P V / C A P E X$. I obtain the mean and standard deviation and

\footnotetext{
${ }^{15}$ In fact, the first tender in the end of 2018 shows exactly that, see Appendix F. Average price premiums across all accepted bids is ca. $3.1 € / M W h$.
} 


\section{Table 1: The Base Case - Assumptions.}

The table provides estimates for a Monte Carlo simulation under the two different subsidy system as well as under no subsidies. Panel $A$ estimates the wind energy investment as requested by the power function in equation (2). Panel B estimates for the Weibull distribution's parameters, see Appendix B. Panel $C$ discloses electricity price forecasts for equation (3). Panel $D$ provides estimates for operational expenditures, specified under equation (20). Finally, Panel E exhibits the remaining information needed for the analysis.

Panel A: Wind Turbine.

\begin{tabular}{lrlr}
\hline$l$ & 50 & $V_{\min }$ & 3 \\
$A\left(=\pi l^{2}\right)$ & 7853.982 & $V_{\max }$ & 18 \\
$\rho$ & 1.28 & $M W_{\max }$ & 3.5 \\
$C_{p}$ & 0.4 & $h$ & 24 \\
\hline
\end{tabular}

Panel B: Wind Speeds.

\begin{tabular}{|c|c|c|c|}
\hline $\begin{array}{l}A \\
k \\
\end{array}$ & $\begin{array}{r}9 \\
2.5 \\
\end{array}$ & & \\
\hline \multicolumn{4}{|c|}{ Panel C: Electricity Price Forecast. } \\
\hline \multicolumn{2}{|c|}{ Stochastic Part } & \multicolumn{2}{|c|}{ Deterministic Part } \\
\hline$\alpha$ & -0.339 & $s_{1}$ & -0.012 \\
\hline$\kappa$ & 23.675 & $s_{2}$ & 0.151 \\
\hline$\sigma_{X}$ & 1.058 & $s_{3}$ & -0.031 \\
\hline$X_{0}$ & -0.121 & $s_{4}$ & -0.042 \\
\hline$\mu_{J}$ & 0.002 & $s_{5}$ & 3.198 \\
\hline$\sigma_{J}$ & 0.187 & $\mu$ & 0.024 \\
\hline$\lambda_{J}$ & 112.966 & & \\
\hline$d t$ & $\frac{1}{365}$ & & \\
\hline
\end{tabular}

Panel D: Subsidies.

\begin{tabular}{lrll}
\hline Old System & & New System & \\
\hline$G$ & 33.5 & $S^{N e w}$ & 17.4 \\
$B$ & 3.1 & & \\
\hline
\end{tabular}

Panel E: Costs.

\begin{tabular}{lr}
\hline$C_{\text {Yearly }}$ & 72,000 \\
$C_{\text {Daily }}$ & 197.26 \\
\hline
\end{tabular}

Panel F: Other.

\begin{tabular}{lrrr}
\hline$r$ & 0.07 & $\beta$ & -0.045 \\
$C A P E X$ & $3,500,000$ & $\mathrm{~T}$ & 9125 \\
$\Delta t$ & $\frac{1}{365}$ & $\mathrm{~N}$ & 1000 \\
\hline
\end{tabular}


graphically illustrate their impact on the profitability ratio. Trends following the variation of these risk parameters exhibit the investment's unique risk exposure.

First, I alter the wind speed scale parameter $A$ under the Weibull distribution from 5 to $15 \mathrm{~m} / \mathrm{s}$. The outcome of this sub-analysis is interesting as disparate geographical locations are subject to varying wind speeds. The results display the environmental conditions' importance for wind energy investments.

Secondly, the drift in the electricity price $\mu$ takes on values between -2 to $6 \%$, allowing for differing expectations for long-run electricity price developments. As the electricity price is one primary driver for the generated income of wind turbine investments, it is vital to acknowledge differences in the electricity price forecast. Investors have diverging expectations of price developments and can easily incorporate them into the valuation model. Moreover, it also provides a threshold in $\mu$ for which the investment is profitable.

Keeping in mind the importance of discount rates in long-term investments as depicted in equation (22), another series of simulations varies it from 0 to $12.5 \%$. The model's outcome provides an approximation under which discount rates the investment opportunity remains profitable. This analysis is interesting as investors have different requirements with regards to the risk-adjusted discount rate.

\subsection{The Equilibrium Bid}

Next to a variation in three chosen risk parameters, I compute an equilibrium bid under which the old subsidy systems is just as promising as the new one. In essence, I vary the subsidy bid in $S_{0}^{N e w}$ from 0 to $25 € / M W h$. For each of the data points in the range given for $S_{0}^{N e w}$, the simulation runs 1000 times and then averages over $P V / C A P E X$. The point where mean in $P V / C A P E X$ under the old subsidy system is equivalent to the mean of $P V / C A P E X$ under the new system is where the two regimes are equally favorable. Under that particular bid, investors would be indifferent under which one they operate.

All other assumptions remain constant as exhibited in Table 1. If other assumption would change, the outcome of the equilibrium bid would also change, so that the results only apply to this specific numerical example. Also, one should keep in mind that the maximum bid is capped at $17.4 € / M W h$, so that bids above are not possible and are just used in this calculation. 


\subsection{Uncertainty in Subsidies}

Finally, I add uncertainty to future subsidy distributions, see Figure 5. Specifically, I vary the likelihood of subsidy cuts through $\lambda_{N e w}$ and $\lambda_{\text {Old }}$ and apply uncertainty in future cash flows according to equation (9)-(19). Here, $\lambda_{N e w}$ and $\lambda_{\text {Old }}$ exhibit yearly subsidy cut probabilities.

Table 2 provides the numerical assumptions for the likelihood and magnitude of subsidy cuts. As in the previous cases, an individual simulation is run for single data points within the ranges of $\lambda_{N e w}$ and $\lambda_{\text {Old }}$. As before, for every single variation, I obtain a means and standard deviations over the distributions for each of the subsidy models.

\section{Table 2: Uncertainty in Subsidies - Assumptions.}

This table provides additional information needed for the analysis of subsidies under uncertainty. Other numerical estimates from Table 1 remain unchanged. The parameters $\lambda^{\text {Old }}$ and $\lambda^{\text {New }}$ are varied within the range of 0 until 0.5 and are expressed in yearly terms. The simulation applies these estimates as defined by equations (9)-(19).

\begin{tabular}{lrlr}
\hline \hline Old System & & New System & \\
\hline$G_{0}$ & 33.5 & $S_{0}^{\text {New }}$ & 17.4 \\
$\lambda^{\text {Old }}$ & 0.5 & $\lambda^{\text {New }}$ & $0-0.5$ \\
$u_{0}$ & 5 & $q_{0}$ & 2.5 \\
$u_{1}$ & 3 & $q_{1}$ & 2 \\
$B$ & 3.1 & & \\
\hline
\end{tabular}

I need to stress that the assumption for subsidy cuts are arbitrary, in particular for $u_{0}, u_{1}, q_{0}$ and $q_{1}$. The reason for $u_{0}$ and $u_{1}$ to be lower in value than $q_{0}$ and $q_{1}$ is that the starting point is under the old subsidy scheme is much higher than under the assumptions of the new subsidy system. The purpose of this simulation to investigate the investment's trend under increases in the probability of subsidy cuts in the future. The findings provide an attempt of quantifying the value of subsidies in the renewable energy industry and help to answer how investors are affected by default probabilities in subsidy distributions. 


\section{Results}

The results are exhibited graphically. I provide findings for the valuation model under the new, old and no subsidy scheme and according to the different specifications outlined in the previous chapter. The focus is on the development of $P V / C A P E X$. This includes the development of mean values in the distributions of simulations as well as the changes in distributions' behavior, denoted by volatility. The lower (higher) the mean, the less (more) profitable the investment opportunity. The higher the volatility, the more uncertain the outcome and thereby profitability of an investment opportunity, and vice versa.

The remainder of this chapter is organized as follows. First, I report the results of the base case scenario. Second, I examine the behavior of $P V / C A P E X$ under a variation in the three risk parameters of wind speeds, electricity price forecasts and discount rates. Moreover, I evaluate the outcome under different subsidy bids in the new subsidy scheme to determine an equilibrium bid under which the two subsidy schemes are equally favorable. Finally, I interpret the findings for the incorporation of default probabilities in future subsidy distributions.

\subsection{The Base Case}

The base case scenario runs a Monte Carlo simulation under the numerical assumptions in Table 1, and separately for the new, old and no subsidy system. Figure 6 reports the findings.

The distributions of all three simulations are close to a normal distributions. The ShapiroWilk test fails to reject at any significant level. Appendix E further exhibits quintile-quintile plots showing strong support of the normal distribution. The standard deviation of the distribution is low. Under the current base case scenario, the project's outcome can be predicted with a high degree of certainty.

A ratio of $P V / C A P E X$ greater than one indicates that the investment is favorable as the initial investment costs are lower than the present value of discounted cash flows. This is the case under all scenarios. However, looking at the case of no subsidies, the investment turns out to be barely profitable as its mean value is just above the threshold. Keeping in mind that the base case values the investment under the assumption of a discount rate of $7 \%$ as well as yearly increase in electricity prices of $2 \%$, most investors would unlikely engage in wind energy without the guarantee 
of additional subsidies.

Looking at both subsidy schemes in wind energy, they are very profitable. The present value of discounted cash flows computes about $70-90 \%$ above the initial investment costs. It comes as no surprise that, under the old subsidy scheme, we have seen a sharp increase in the total capacity installs over the previous decades, see Figure C.

The two subsidy compensation systems yield not far apart from each other. The old subsidy compensation system ranks a little higher than the new scheme. The new subsidy system is run under the assumption of the maximum bid allowed, which is unrealistic to occur in the tendering process, see Appendix F. Considering that the subsidy-free scenario is profitable in itself, the narrative of low bids in the future gains validity. This will eat up parts of the investments' value, however, considering a margin of about $70 \%$ under the maximum bid, they will stay profitable for bids much lower. Creating competition through budget constraints, meaning that only the lowest bids are accepted until the budget for a tender runs out, will even force investors to place lower bids, in this case $S^{N e w}$, and give up some of their investment's return. It is be better for investors to give up some of the subsidy value instead of not being granted any subsidy compensation at all by bidding too high. Considering that lower bids will likely occur at future auctions implicates that the old subsidy compensation scheme was more profitable in comparison to the new tender-based system from an investor's perspective.

As mentioned before, the comparison of the two subsidy systems to the case of no subsidies in in Figure 6, makes clear that subsidies make up a large share of the total investment. This conclusion strengthens the hypothesis that renewable energy investments in Denmark are still dependent on additional subsidy compensation and are not yet in a position, where they can compete with subsidy-free, traditional energy production. On the other hand, considering the present value of subsidies of more than $2 / 3$ of the total investment, also empowers the previous assumption that investors can afford to give up parts of that share by placing low bids at the annual auctions. It is therefore and due to budget constraints highly unlikely that bids close to the maximum bid of $€ 17.4 / \mathrm{MWh}$ will occur in any of the tenders. 
Figure 6: Distribution of Income Simulation in the Base Case.

The figure exhibits three histograms each drawing from 1000 outcomes of $P V / C A P E X$ based on equation (22), the assumptions of Table 1 and under the old, new and subsidy-free (No S.) systems. Under the old subsidy system investors are compensated with $25 \varnothing \mathrm{re} / \mathrm{kWh}(€ 33.5 / \mathrm{MWh})$ for the first 22.000 full load hours on top of $2.3 \varnothing \mathrm{re} / \mathrm{kWh}(€ 3.1 / \mathrm{MWh})$ balancing costs for electricity over the lifetime of a project. Under the new subsidy system, investors are compensated with €17.4/MWh, which is the maximum bid under the compensation system. Assuming no subsidies, investors receive no additional compensation apart from the market price to which they sell their electricity.

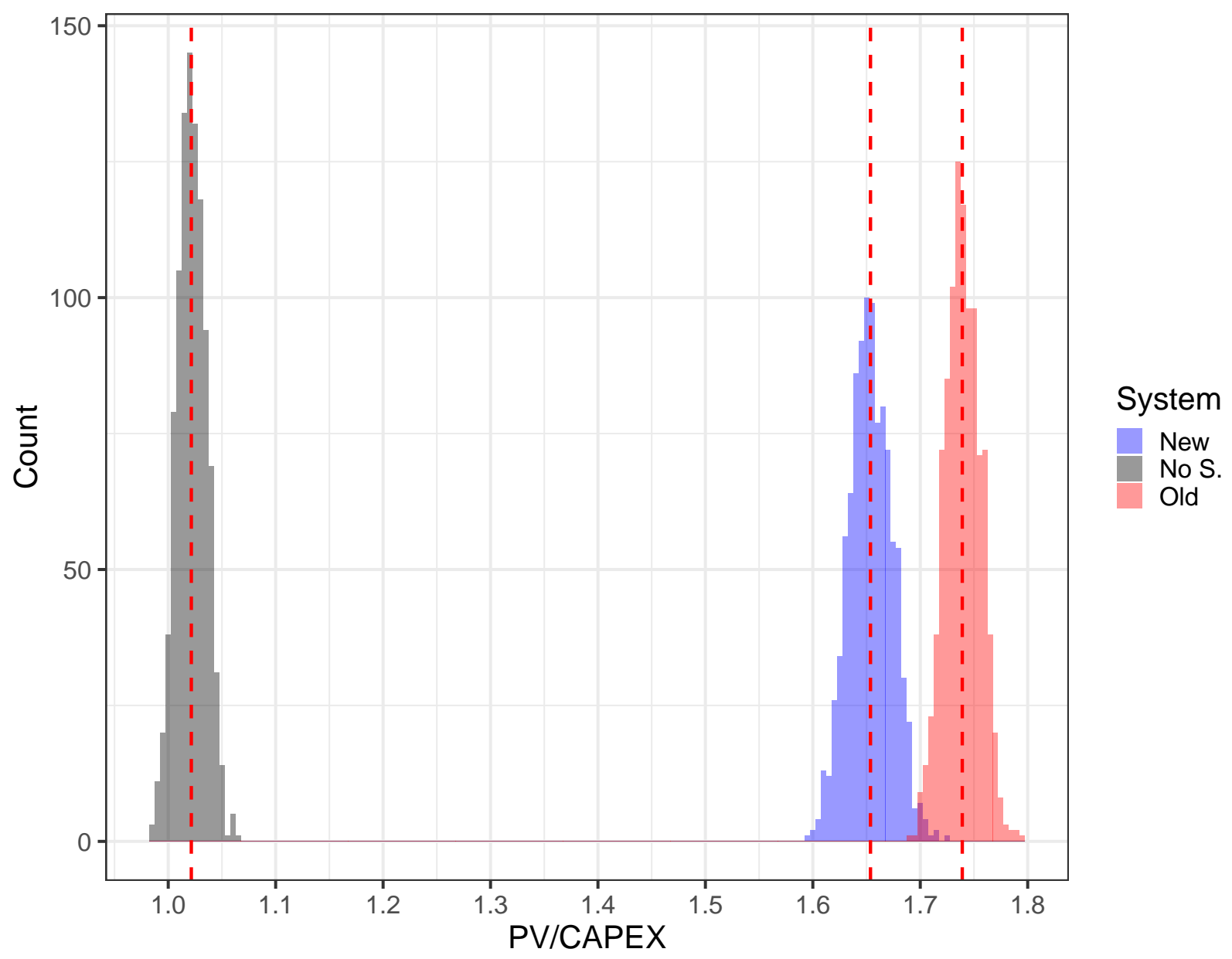

\subsection{Varying Risk Parameters}

The second simulation exercise varies the base in a number of uncertainty parameters. The other assumptions as defined in Table 1 stay fixed, while varying only one variable at a time. I vary the scale parameter in wind speeds, the drift in the long run projection of electricity prices, and the discount rates applied to future cash flows estimations. Figure 16 displays the results under the old, new and subsidy-free (No S.) systems. 
Figure 16a and 16b display a changing wind speed scale parameter $A$ in relation to the investment's valuation. This is important to consider, because different geographical locations are exposed to different environmental conditions, including wind speeds.

The first observations is that for higher wind speeds the investment's value increases, see Figure 16a. It sharply increases under all subsidy schemes from $5 \mathrm{~m} / \mathrm{s}$ up until about $10 \mathrm{~m} / \mathrm{s}$. The breakthrough to profitability comes at around $A=7-7.5 \mathrm{~m} / \mathrm{s}$ for the old and new subsidy scheme. The subsidy-free based system turns profitable at around $A=8.5 \mathrm{~m} / \mathrm{s}$. Though with less intensity, the slope keeps climbing after $10 \mathrm{~m} / \mathrm{s}$ until a maximum level of about $13 \mathrm{~m} / \mathrm{s}$ and then slowly decreasing again. This decrease is due to the fact that the wind turbine, in this example, has a cut-off level $V_{\max }$ of $18 \mathrm{~m} / \mathrm{s}$. The higher the scale parameter $A$, the more days occur under which the turbine is turned off because of wind speeds exceeding $V_{\max }$ and therefore not generating income. Moreover, the volatility in draws of $P V / C A P E X$ increase with an increase in the scale parameter $A$. This comes to no surprise as a higher scale parameter indicates a higher variability in the daily wind speed averages, see Figure B. In a nutshell, the environmental conditions with regards to wind speeds are a vital factor for wind energy investments.

Furthermore, it is interesting to see that the old and new subsidy systems cross at a given scale parameter of approximately 10m/s, see Figure 16a. Also, at higher productivity levels, the new system increases more in profitability than the old system. This is due to the fact that the new subsidy system is not bound by total production, but instead by time, so that higher productivity is promoted to a larger extent. The new system thereby encourages investors to build more productive wind turbines to best exploit the new subsidy system.

Finally, the higher the scale paramater $A$ is, the higher the volatility in the distribution becomes, see Figure 16b. A higher scale parameter means more volatility in cash flows, leading to more volatility in cash flows over time and therefore more variability in present values.

Figure $16 \mathrm{c}$ and $16 \mathrm{~d}$ exhibit a sensitivity analysis with regards to varying expectations in longterm developments of electricity prices, denoted by $\mu$. It comes to no surprise that an increase in $\mu$ yields a monotonically increasing ratio of $P V / C A P E X$. The electricity price is, next to only subsidies, the only source of income. High electricity price yield high income, and vice versa. The project's value is highly dependent on the outlook of the electricity price, see Figure 16c. An outlook of a yearly increase in the electricity price of about $4 \%$ annually lead to a present value of 
future cash flows of more than twice the initial investment.

The old and new subsidy scheme stay profitable even under consideration of a drift of $-2 \%$. Investments under the subsidy-free subsidy scheme, however, cannot allow any negative drift in future electricity prices, which might be one reason investors barely engage in wind energy without additional compensation. Fear of negative or very low future growth rates in electricity prices will make these investments unprofitable immediately. The volatility of present values of future cash flows also increases along with surging drifts. This is reasonable as cash flows deviate further from the average mean over time with rising electricity prices.

Finally, Figures $16 \mathrm{f}$ and $16 \mathrm{f}$ disclose how the valuation in wind energy relies on discount rates. Wind energy investments are long-term and the chosen time-horizon for this numerical application is 25 years, making the investment itself highly dependent on discount rates. Even small incremental changes in the assumption of the discount rate yield significant changes in the investment's valuation. In this example, investors with a required return of more than ca. $8.5 \%$ will find themselves in a position, where they would chose not to invest under the subsidy-free system. Interestingly, the old and new subsidy schemes cross at a discount rate of a little over $3 \%$. The new subsidy scheme yields higher income at later points in the project's life-time because of the comparatively long eligibility of 20 years. The old subsidy scheme, however, only grants subsidies for the first 22.000 full-load hours. These first 22.000 full-load hours are typically exhausted after the first 5-7 years. This means that cash flows are higher in the beginning of the project in comparison to the new subsidy scheme as the old scheme grants $33.5 € / M W h$ in comparison to a maximum of $17.4 € / M W h$. If the discount rate rises, cash flows in the distant future are discounted more heavily in comparison to cash flows in the near future, which is why the the new system is more profitable for very low rates.

\subsection{The Equilibrium Bid}

The old and the new subsidy scheme differ in their construction. While the old system is a fixed topup of $33.5 € / M W h$ to the electricity price, the new system organizes yearly auctions, where investors place bids for the additional compensation per MWh they wish to receive. In this chapter, I keep the assumptions from Table 1 fixed except for varying the parameter of $S^{N e w}$ and thereby run the new subsidy scheme under different bids. I run the analysis for changing bids in $S^{N e w}$ from 0 to 
Figure 7: Varying Risk Parameters.

The Figures exhibit the outcome of a variation in a single uncertainty parameter while keeping all other assumption from the base case in Table 1 fixed. Each data point in the graphs represents the mean value of $P V / C A P E X$ over 1000 draws. In particular, the figures represent variations in wind speeds, electricity price drifts, and discount rates.

(a) Changing Wind Speeds.

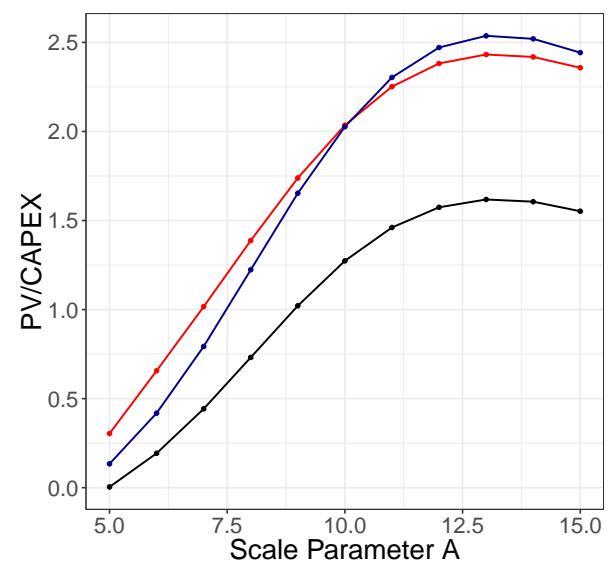

(c) Drift in Electricity Prices.

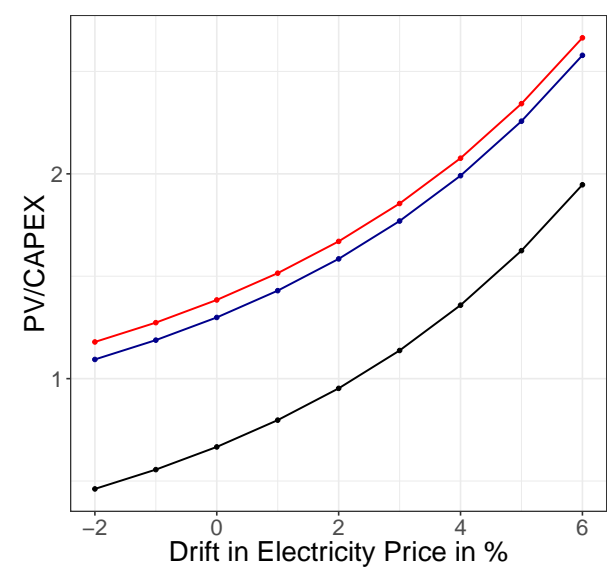

(e) Changing Discount Rates.

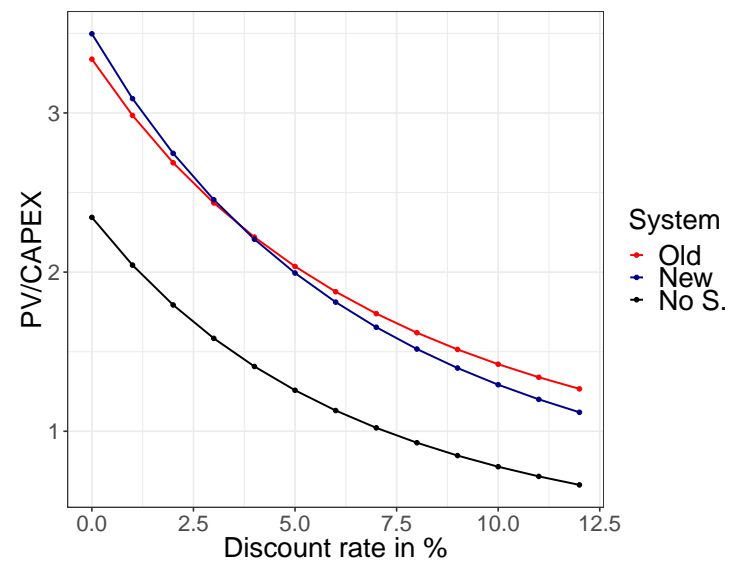

(b) Wind Speeds and Volatility.

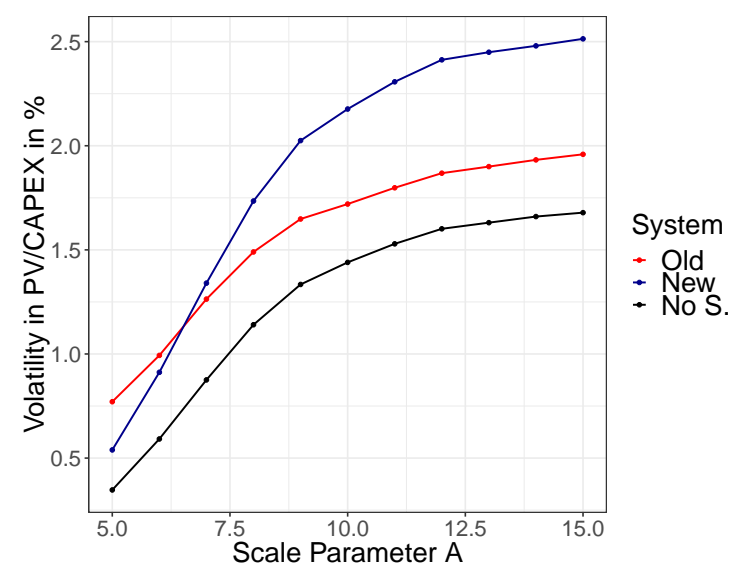

(d) Electricity Prices and Volatility.

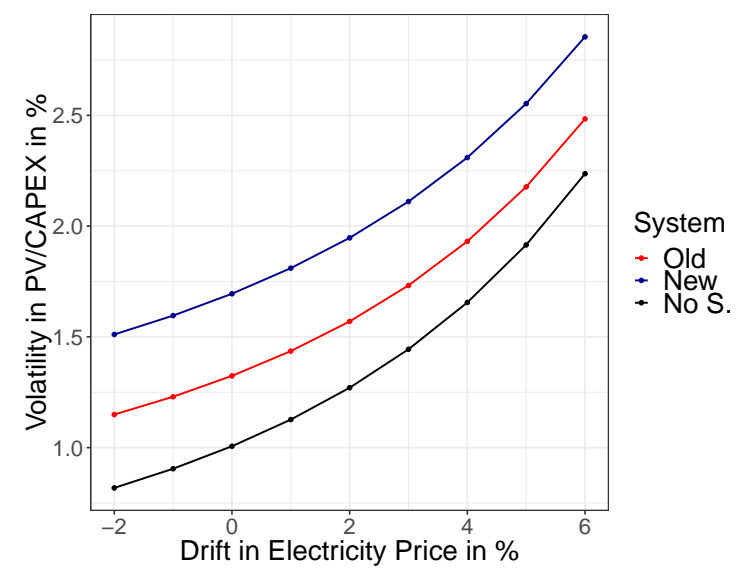

(f) Discount Rates and Volatility.

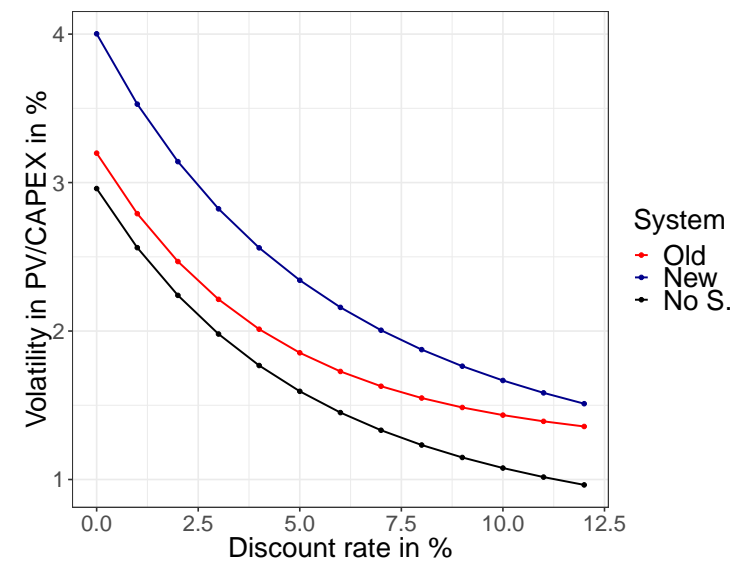


$25 € / M W h$ despite the fact that, in the real world, $S^{N e w}$ is capped at $17.4 € / M W h$. Figure 8 display the results.

The old and the subsidy-free systems remain unaffected to the bids in the new subsidy compensation scheme as they are unrelated to $S^{N e w}$. The new subsidy compensation increases linearly to the amount of the amount of subsidy bids. The more the subsidy distribution increases in $S^{\text {New }}$, the more profitable the investment is. Cash flow rise and so does the present value of the sum of cash flows.

I find an equilibrium of the new and old subsidy scheme at $S^{N e w} \approx 20 € / M W h$, which is above the maximum bid allowed. Everything below $20 € / M W h$ yields lower present values than under the old subsidy system, so that investors will almost certainly be worse off (given the assumptions in Table 1). At $S^{N e w}=0 € / \mathrm{MWh}$, the assumptions are the same as in the subsidy-free scenario and therefore yield the same outcomes.

Interestingly, volatility increases with higher degrees of $S^{\text {New }}$. Nevertheless, it becomes clear that higher subsidy compensation must also lead to higher volatility throughout the entire project due to the final five years of the project. The average differences between cash flows of the first 20 years and the last five years, which are subsidy-free by default, rises with a higher compensation through $S^{N e w}$.

\subsection{Uncertainty in Subsidies}

Finally, I consider uncertainty in subsidy compensation over time according to equations (9)-(19). The assumption of the base case scenario in Panel D in Table 1 are exchanged by Table 2. The parameters of $\lambda^{\text {Old }}$ and $\lambda^{\text {New }}$ depict yearly probability of subsidy cuts, which the simulation varies between 0 and $50 \%$ and, through the computation, transforms to daily approximations by $\Delta t$. Figure 9 shows the results.

The two subsidy schemes, old and new, react negatively to an increase in the probability of subsidy cuts. It comes to no surprise that the higher the probability, the less valuable the investments. What is worthwhile noting, however, is that the new subsidy compensation system reacts more heavily to surging default probabilities. The trivial explanation behind this observation is that the new subsidy system distributes payouts over a much longer time horizon, implicating a longer exposure to the risk of subsidy cuts. Under any circumstance, the new subsidy system is 
Figure 8: Changing Subsidy Bids.

The Figures $8 \mathrm{a}$ and $8 \mathrm{~b}$ exhibit the variation in a the single parameter of parameter $S^{\text {new }}$ while keeping all other assumption from the base in Table 1 fixed. Each data point in the graphs represents the mean value of $P V / C A P E X$ over 1000 draws. As the old and subsidy-free system are not affected by differences in the bids of $S^{n e w}$, they remain constant.

(a) The Equilibrium Bid.

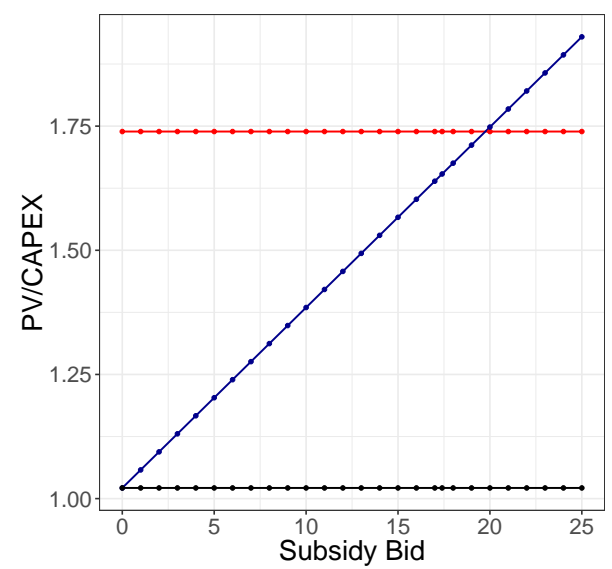

(b) Volatility under different Bids.

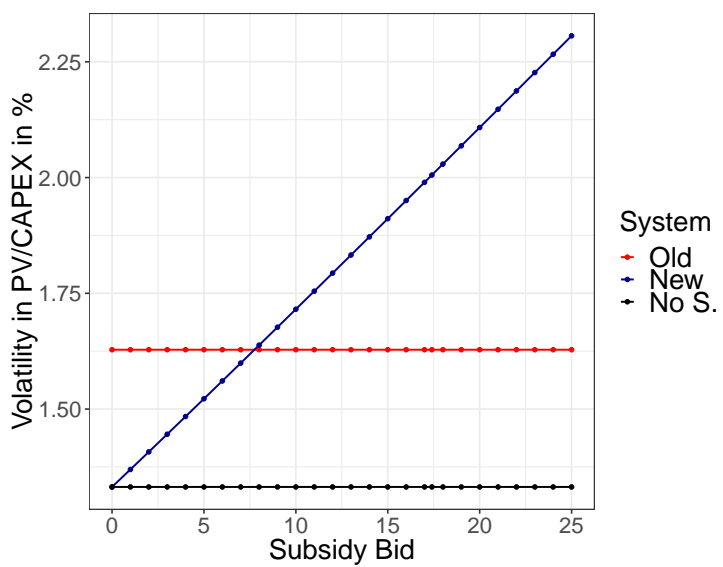

slightly more profitable than the old one. Again, it should be noted that the simulation assumes the maximum bid of $17.4 € / \mathrm{MWh}$, so that the old system is likely to be much more profitable than displayed in Figure 9b. By nature, the subsidy-free system does not react to subsidy default probabilities as it does not receive any type of additional compensation in the first place.

The volatility in the draws of $P V / C A P E X$ increases in accordance with the default probability in subsidy distributions over time under both the old and new system up until about 35\%. An increase in the probability of subsidy cuts lead do differences in subsidy compensations over time and therefore increases the volatility in cash flows. This effect is higher under the new system, which is, once more, due to its longer exposure to subsidy cuts. After $35 \%$ in the yearly default probability, the new system goes back in volatility. A higher default probability in $\lambda^{N e w}$ leads to significant subsidy cuts early in the project lifetime and therefore reduces risk as measured by the distribution of cash flows over time.

\section{Concluding Remarks}

This paper introduces a general income and valuation model for wind energy projects, focusing on the Danish market. It takes into account the novel production function of wind turbines, allowing 


\section{Figure 9: Uncertainty in Subsidies.}

The Figures 9a and 9b exhibit uncertainty in the subsidy compensation of $S^{\text {Old }}$ and $S^{N e w}$. The assumption from the base in Table 1 are partly redefined by Table 2. The simulation varies $\lambda^{\text {Old }}$ and $\lambda^{\text {New }}$, expressing the default probability. Each data point in the graphs represents the mean value of $P V / C A P E X$ over 1000 draws. As the subsidy-free system (No S.) is not eligible for subsidies, it is not affected by default probabilities in subsidy cuts.

(a) Uncertainty in Subsidies.

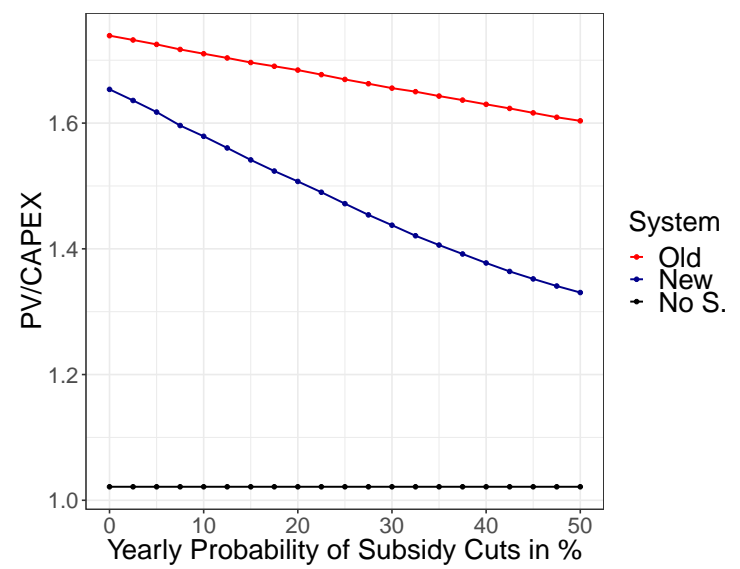

(b) Subsidy Defaults and Volatility.

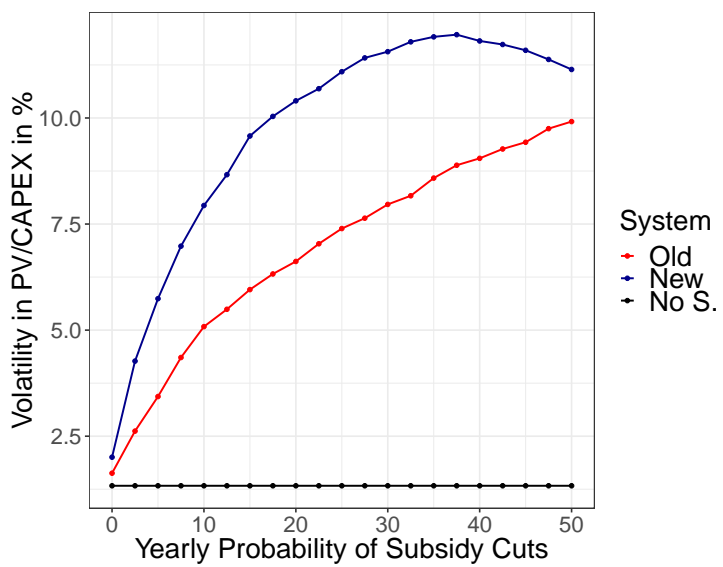

to value investments under the precise technical details of the turbine itself and the uncertainty parameter of wind speeds. I put the model to the test through a numerical application to value a hypothetical investment opportunity. The analysis itself investigates changes in different risk parameters and the introduction of a new subsidy system in comparison to the previously abolished old system. Moreover, the analysis considers a subsidy-free wind energy investment.

There are four primary findings. First, wind energy investments appear to be exposed to little risk under the premise of fixed assumptions in the price of electricity, a good understanding of the environmental conditions of the location (e.g. wind speeds), a fixed discount rate, and no uncertainty in future subsidy cuts, see Figure 6. The standard deviation of this base-case scenario distribution is small.

Secondly, the analysis exposes the investment to a variation of risk parameters. The main findings are that long-term wind energy investments are highly dependent on the scale parameter of wind speeds, the future outlook of electricity prices and changing discount rates. In particular, the scale parameter $A$ profoundly impacts wind energy performance.

Third, the new subsidy system seems less profitable than the old system. The new subsidy system is that of a tender process through which investors place bids in yearly auctions and, 
if granted, receive additional payouts for 20 years. The old system, however, compensates wind energy operators with a predefined top-up to the electricity price for a limited number of production hours. The newly introduced tender-based system appears to be inferior to the old subsidy scheme. Under the assumption of an equilibrium bid of $S^{N e w} \approx 20 € / M W h$, the two subsidy schemes are equally profitable. However, this bid is not permissible to place as a maximum of $17.4 € / \mathrm{MWh}$ constrains investors in the auctions. Nevertheless, they are both more favorable than a subsidyfree investment opportunity in wind energy. Acknowledging the fact that the new subsidy is less favorable than the old system, further leads to the suggestion of a decrease in new installments over the years to come. It is thereby unlikely that the trend of the last ten years will continue in the near future, see Figure 10.

Generous subsidies in the Danish energy market is one reason for Denmark to lead the world in renewable energy production. This paper shows that they play a significant role from an investor's perspective when financing wind energy projects in Denmark. Because of its vital significance, the analysis further introduces uncertainty in future subsidy distributions by assuming default probabilities in subsidy distributions throughout a project's lifetime. It finds that the new scheme is more sensitive towards risk of subsidy cuts as investors receive payouts over a much longer time horizon, and consequently, they are exposed to default probabilities much longer. Moreover, the assumption of default probabilities in subsidies payouts leads to a higher standard deviation in cash flows and thereby makes the investment riskier.

It is likely that the bids in the upcoming tenders will be much lower than the maximum bid allowed, considering wind energy investments have been remarkably profitable under the old subsidy system. In fact, the first tender of 2018 shows just that with a weighted average bid of $2.28 \varnothing \mathrm{re} / \mathrm{kWh}(0.31$ Eurocent $/ \mathrm{kWh}$ or $3.1 € / \mathrm{MWh})$, which is far away from the maximum bid allowed, see Appendix F. This also confirms the narrative of the paper that the maximum bid of $17.4 € / M W h$ is somewhat unrealistic and investors will need to calculate with a number much lower.

In a nutshell, it seems that wind energy projects, at this point, represent a profitable investment opportunity only if they receive subsidies in addition to the market price of electricity. On the flipside, however, they are accompanied by additional sources of uncertainty, some of which we are not certain how to accurately define yet. In particular, investors with no exposure or experience might find it very challenging to think of these unique sources of risk. 
The proposed model of this paper suggests a way for these investors to assess wind energy projects. It can be universally applied to forecast income and value investment opportunities. In particular, it serves as a unique and explicit way to determine future daily cash flows under the precise definition of the wind turbines in question. In combination with the production function of wind turbines, it allows for the variation of a plethora of parameters. This includes wind speeds, the long-term forecast of electricity prices, discount rates or uncertainty in subsidies. Finally, the model might be useful for Danish investors to determine the optimal bid under which they are willing to fund new wind energy projects.

There are potential inaccuracies and unanswered questions that open avenues for future research. For, example, the variable definition of Table 2 might deviate from today's reality. I attempted to find a suitable and educated guess for each of the parameters, but might be off on some of the chosen numerical assumptions in the application. Moreover, the paper does not answer the question of how wind energy investment's valuations change under changing operation horizons. Adding or subtracting only a few numbers of years from the presumed operating time of 25 years will likely change the valuation estimates by significant margins. Also, the analysis does not consider more or less productive turbines. I assume that under the assumption of similar initial investment costs but more productive turbines, the new subsidy system will have a better chance to minimize the difference to the old system with regards to profitability, simply because production limits do not bind payouts, but only time does. This way, Denmark implemented incentives for investors to build more powerful wind turbines in the future to best exploit the new subsidy scheme. However, this question remains unanswered in the analysis and opens a door for another hands-on analysis. 


\section{References}

Amirat, Y., Benbouzid, M. E. H., Al-Ahmar, E., Bensaker, B., and Turri, S. (2009). A brief status on condition monitoring and fault diagnosis in wind energy conversion systems. Renewable and sustainable energy reviews, 13(9):2629-2636.

Barcelona, R. G. (2017). Energy Investments: An Adaptive Approach to Profiting from Uncertainties. Springer.

Bodie, Z., Kane, A., and Marcus, A. (2009). Investments. Irwin series in finance. McGraw-Hill.

Cutler, N. J., Boerema, N. D., MacGill, I. F., and Outhred, H. R. (2011). High penetration wind generation impacts on spot prices in the australian national electricity market. Energy Policy, 39(10):5939-5949.

Dixit, A. K., Dixit, R. K., Pindyck, R. S., and Pindyck, R. (1994). Investment under uncertainty. Princeton university press.

Escribano, A., Ignacio Peña, J., and Villaplana, P. (2011). Modelling electricity prices: International evidence. Oxford bulletin of economics and statistics, 73(5):622-650.

Gryning, S.-E., Floors, R., Peña, A., Batchvarova, E., and Brümmer, B. (2016). Weibull wind-speed distribution parameters derived from a combination of wind-lidar and tall-mast measurements over land, coastal and marine sites. Boundary-Layer Meteorology, 159(2):329-348.

Johnson, N. L., Kemp, A. W., and Kotz, S. (2005). Univariate discrete distributions, volume 444. John Wiley \& Sons.

Lucia, J. J. and Schwartz, E. S. (2002). Electricity prices and power derivatives: Evidence from the nordic power exchange. Review of derivatives research, 5(1):5-50.

Rathmann, M. (2007). Do support systems for res-e reduce eu-ets-driven electricity prices? Energy policy, 35(1):342-349.

Seifert, J. and Uhrig-Homburg, M. (2007). Modelling jumps in electricity prices: theory and empirical evidence. Review of Derivatives Research, 10(1):59-85.

Villaplana, P. (2003). Pricing power derivatives: A two-factor jump-diffusion approach. 
Villaplana Conde, P., Peña Sánchez de Rivera, J. I., Escribano Sáez, Á., et al. (2002). Modeling electricity prices: international evidence. Technical report, Universidad Carlos III de Madrid. Departamento de Economía.

Wan, Y.-H., Ela, E., and Orwig, K. (2010). Development of an equivalent wind plant powercurve: Preprint. Technical report, National Renewable Energy Lab.(NREL), Golden, CO (United States).

Würzburg, K., Labandeira, X., and Linares, P. (2013). Renewable generation and electricity prices: Taking stock and new evidence for germany and austria. Energy Economics, 40:S159-S171.

Yu, Z. and Tuzuner, A. (2008). Wind speed modeling and energy production simulation with weibull sampling. In Power and Energy Society General Meeting-Conversion and Delivery of Electrical Energy in the 21st Century, 2008 IEEE, pages 1-6. IEEE. 


\section{Appendices}

\section{A The Wind Energy Market in Denmark}

Figure 10: Capacity Installs in Denmark from 1980 until 2016.

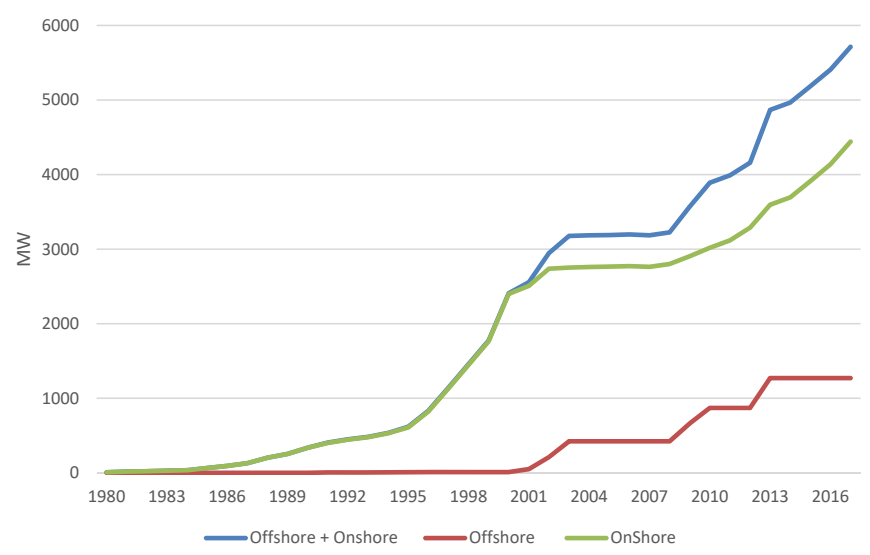

Source: Bloomberg New Energy Finance (BNEF). 


\section{B The Weibull Distribution}

Consisting of two parameters, the Weibull distribution density probability density function $f(v)$ applied to the average wind $v$ states as

$$
f(v)=\frac{k}{A}\left(\frac{v}{A}\right)^{k-1} \exp \left(-\left(\frac{v}{A}\right)^{k}\right),
$$

in which $A$ and $k$ depict the scale and shape parameter, respectively. The average wind speed $E(V)$ and the variance $\operatorname{Var}(V)$ are defined as

$$
\begin{gathered}
E(V)=A \Gamma\left(1+\frac{1}{k}\right) \\
\operatorname{Var}(V)=A^{2}\left(\Gamma\left(1+\frac{2}{k}\right)^{2}\right),
\end{gathered}
$$

where $\Gamma$ exhibits the Gamma function (Yu and Tuzuner, 2008). To model average daily wind speeds of $\bar{V}_{t}$, I use this Weibull distribution through an educated guess of $k$ and $A$ and with the help of of the $R$-package 'stats4' and the corresponding function rweibull(n, shape, scale).

\section{Figure 11: The Weibull Distribution.}

The Weibull distribution is assumed throughout the simulation of future income with a scale parameter of $A=9$ and a shape parameter of $k=2.5$.

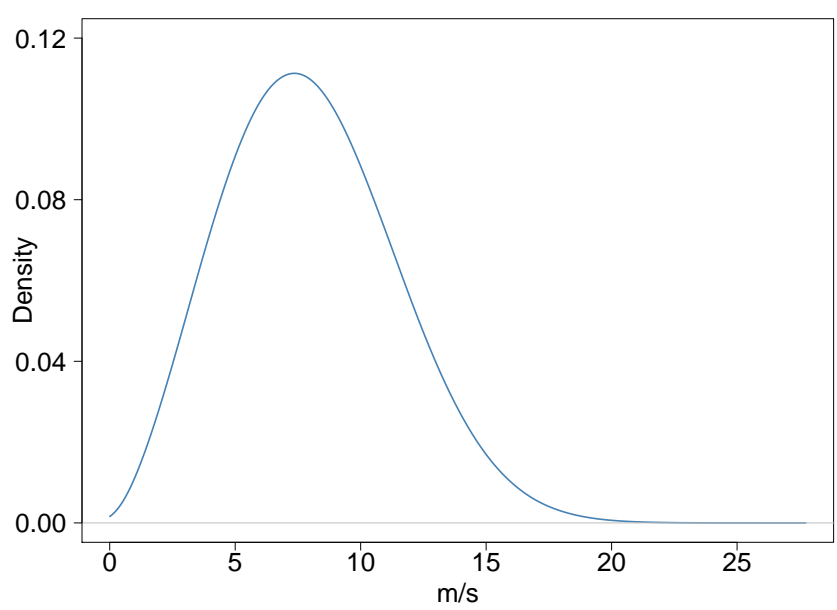


Figure 12: Wind Speeds in Denmark.

Figure 12a exhibits weekly and 30-Year-Median Wind Speeds in $\mathrm{m} / \mathrm{s}$ over time. Figure $12 \mathrm{~b}$ displays the distribution of weekly median wind speeds in Denmark, measured in m/s. Source: Bloomberg New Energy Finance (BNEF).

(a) Wind Speeds over Time.

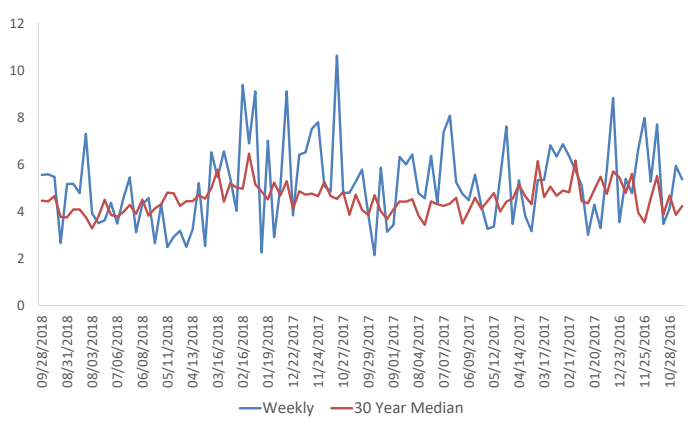

(b) Wind Speed Distribution

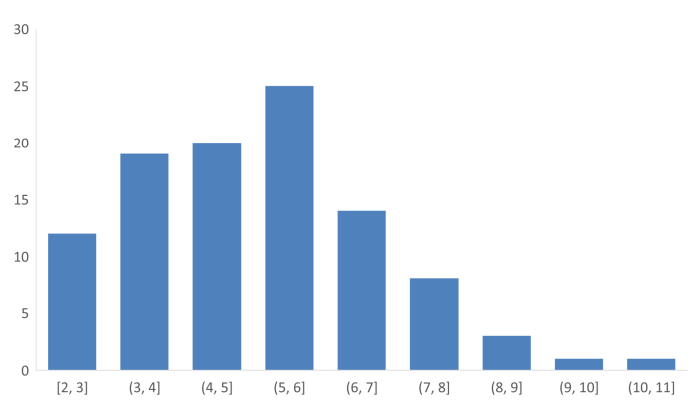




\section{Electricity Price Forecasts}

Figure 13: Histograms.

The distributions in subfigures $13 \mathrm{a}$ and $13 \mathrm{~b}$ depict the actual daily average spot price and $\log ($ price) of the Nordic electricity market irrespective of capacity congestion in the individual interconnections between the areas of Denmark, Sweden and Germany (referred to as SYSTEM) and obtained from Energi Data Service. Figures $13 \mathrm{c}$ and $13 \mathrm{~d}$ exhibit the simulated price and $\log$ (price) distributions.

(a) Price Distribution.

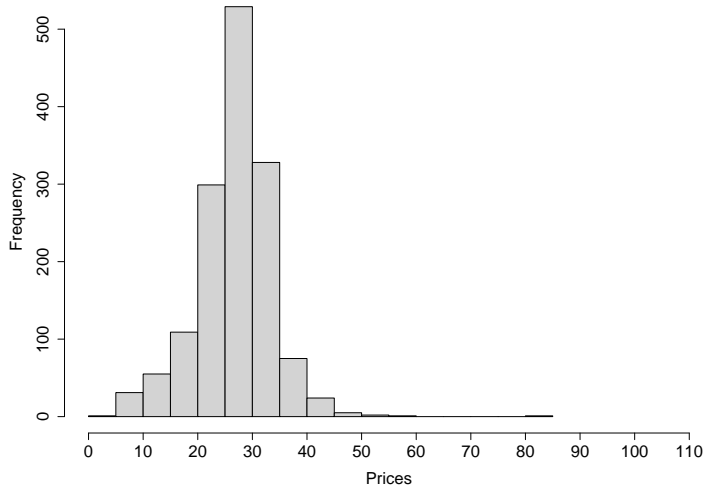

(c) Simulated Price Distribution.

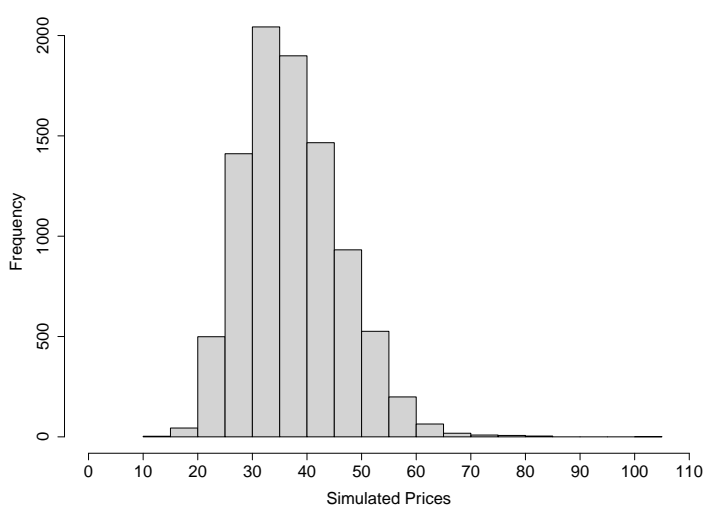

(b) Log Price Distribution.

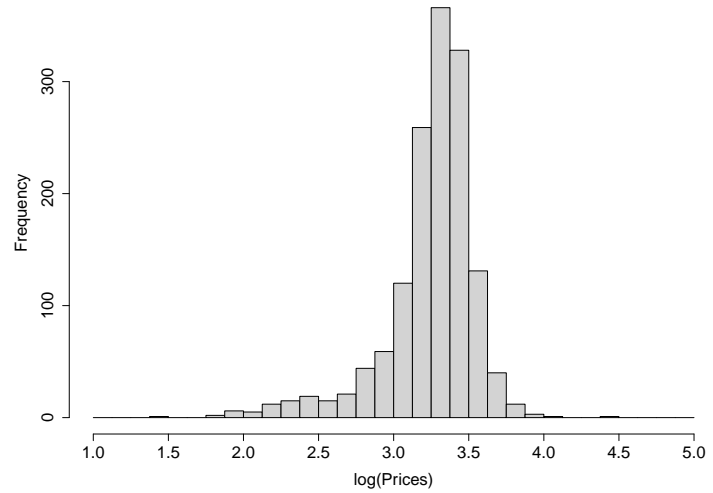

(d) Simulated Log Price Distribution.

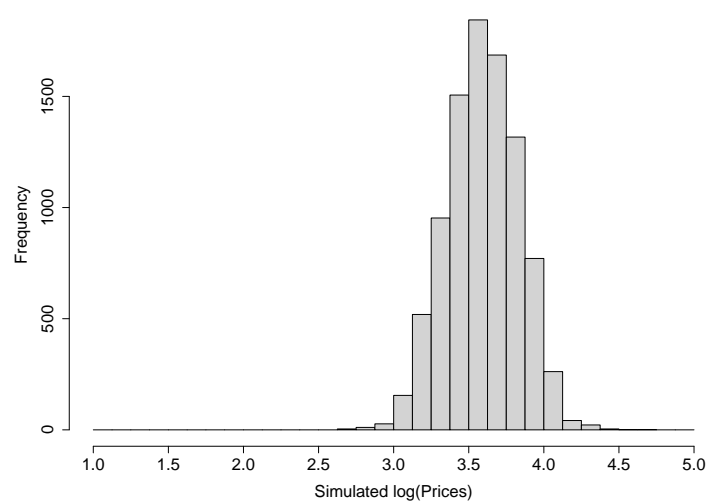




\section{Price vs. Production}

\section{Table 3: The Impact of Production.}

The table exhibits the results of regressions of daily electricity prices from 2015 until 2017 against production. Prices are exhibited as log-prices. Production $t$ is measured by the ratio of daily production at time $t$ over the average of the time series. The numbers in parenthesis exhibit standard errors while the stars denote significance levels. Data Source: Nord Pool AS.

\begin{tabular}{|c|c|c|c|}
\hline & \multicolumn{3}{|c|}{ Dependent variable: } \\
\hline & \multicolumn{3}{|c|}{$\log \left(\mathrm{P}_{t}\right)$} \\
\hline & $(1)$ & $(2)$ & $(3)$ \\
\hline Production $_{t}$ & $\begin{array}{c}-0.045^{* * *} \\
(0.012)\end{array}$ & $\begin{array}{c}-0.044^{* * *} \\
(0.005)\end{array}$ & $\begin{array}{c}-0.045^{* * *} \\
(0.005)\end{array}$ \\
\hline $\log \left(\mathrm{P}_{t-1}\right)$ & & $\begin{array}{c}0.921^{* * *} \\
(0.010)\end{array}$ & $\begin{array}{c}0.877^{* * *} \\
(0.026)\end{array}$ \\
\hline $\log \left(\mathrm{P}_{t-2}\right)$ & & & $\begin{array}{l}0.048^{*} \\
(0.026)\end{array}$ \\
\hline Constant & $\begin{array}{c}3.290^{* * *} \\
(0.014)\end{array}$ & $\begin{array}{c}0.299^{* * *} \\
(0.032)\end{array}$ & $\begin{array}{c}0.288^{* * *} \\
(0.033)\end{array}$ \\
\hline Observations & 1,461 & 1,460 & 1,459 \\
\hline Adjusted $\mathrm{R}^{2}$ & 0.009 & 0.858 & 0.858 \\
\hline
\end{tabular}




\section{Figure 14: Prices and Production.}

The graph plots log-prices of the daily electricity spot price against production. The red line (regression of the log price against the daily production ratio over its mean), inidcates a minor but yet significant negative causality, see Table 3. Data Source: Nord Pool AS.

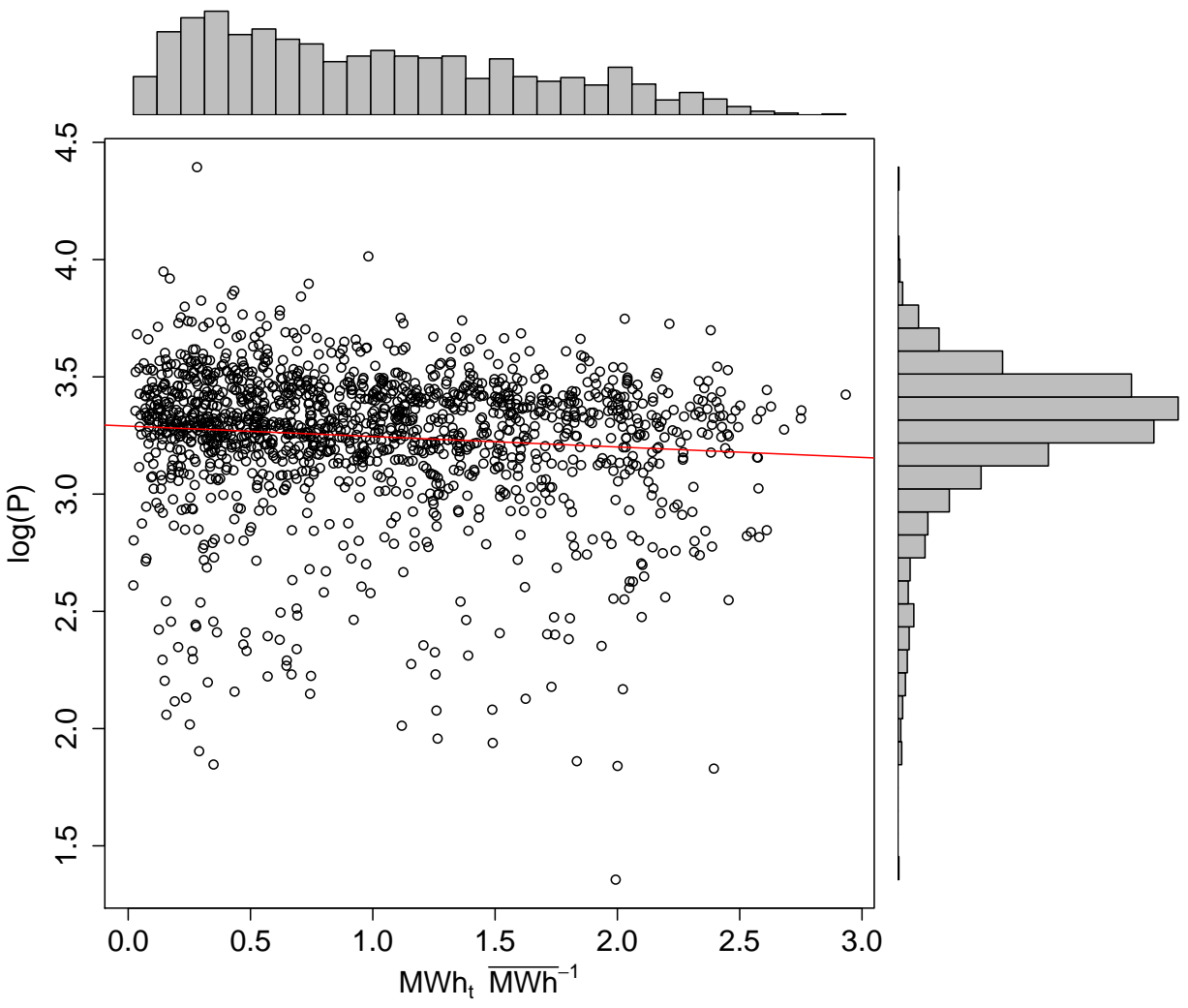




\section{E The Base Case Simulation}

\section{Figure 15: Quantile-Quantile Plots.}

The Figures 15a, 15b and 15c each exhibit the deviation of 1000 outcomes of $P V / C A P E X$ based on Figure 6 , the old, new and subsidy-free systems and under base case scenario of Table 1 from the normal distribution (red line). Under the old subsidy system, investors are compensated with $25 \varnothing \mathrm{re} / \mathrm{kWh}(€ 33.5 / \mathrm{MWh})$ for the first 22.000 full load hours on top of $2.3 \varnothing \mathrm{re} / \mathrm{kWh}(€ 3.1 / \mathrm{MWh})$ balancing costs for electricity over the lifetime of a project. Under the new subsidy system, investors are compensated with €17.4/MWh, which is the maximum bid under the new subsidy compensation system. Assuming no subsidies, investors receive no additional compensation apart from the market price to which they sell their electricity.

(a) The old Subsidy System.

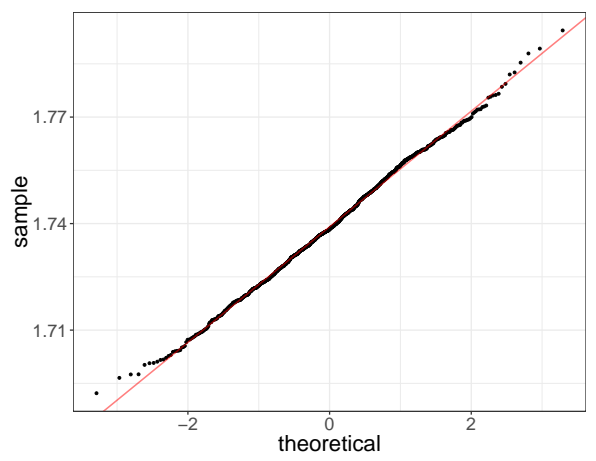

(b) The new Subsidy System.

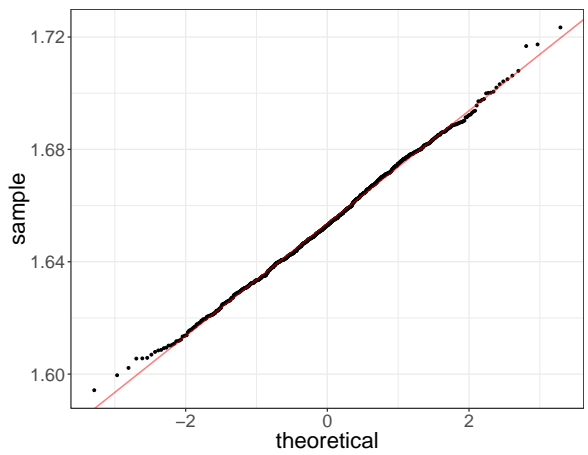

(c) Subsidy-free System.

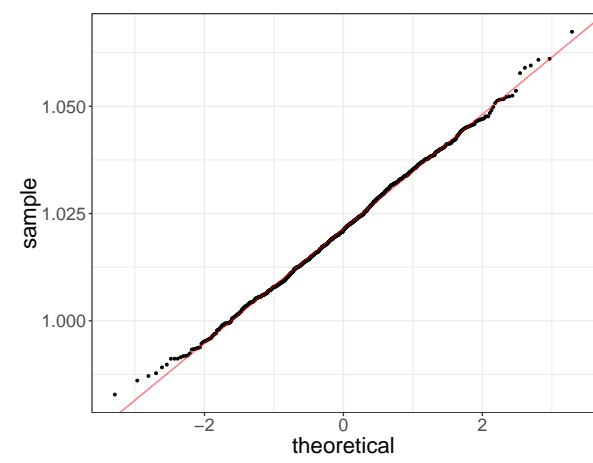




\section{F The first Tender 2018}

Table 4: Fact Sheet on the Result of the Technology Neutral Tender 2018.

The Danish Energy Agency called for bids in the first technology neutral tender 27 September 2018, with a deadline for bids on 26 November 2018. The budget for the tender was $254 \mathrm{mDKK}$. The DEA has received in total 17 bids with projects of approx. 260MW onshore wind turbines and approx. 280MW solar PV installations. It is expected that 6 contracts will be signed, including 3 contracts with approx. $165 \mathrm{MW}$ onshore wind turbines and 3 contracts with approximately 101MW solar PV installations. This corresponds to approx. $200 \mathrm{MW}$ onshore wind turbines equivalents or the electricity consumption of approximately 160,000 Danish households. The weighted average price premium of the winning bids is $2.28 \varnothing \mathrm{re} / \mathrm{kWh}$ or approx. 0.31Eurocent/kWh.

\begin{tabular}{|c|c|c|c|c|c|}
\hline Winners & Technology & $\begin{array}{r}\text { Offered Price } \\
\text { Premium }(\varnothing \mathrm{re} / \mathrm{kWh}) \\
\end{array}$ & Capacity (MW) & $\begin{array}{r}\text { Share of } \\
\text { budget }\end{array}$ & Municipality \\
\hline 1. NRGi Wind V A/S & Wind & 1.89 & 28.8 & 11.9 & Thisted \\
\hline 2. K/S Thorup-Sletten & Wind & 1.98 & 77.4 & 33.5 & $\begin{array}{l}\text { Jammerbugt and } \\
\text { Vesthimmerland }\end{array}$ \\
\hline 3. SE Blue Renewables DK P/S & Wind & 2.50 & 59.3 & 32.4 & Randers \\
\hline 4. Solar Park Rødby Fjord ApS & Solar & 2.84 & 60.0 & 12.7 & Lolland \\
\hline 5. Solar Park Næssundvej ApS & Solar & 2.84 & 30.0 & 6.3 & Mors $\varnothing$ \\
\hline 6. Better Energy Frederikslund Estate ApS & Solar & 2.98 & 11.5 & 3.1 & Slagelse \\
\hline
\end{tabular}

Source: Energistyrelsen. 


\section{Figure 16: Varying Risk Parameters.}

The Figures exhibit the outcome of a variation in a single uncertainty parameter while keeping all other assumption from the base case in Table 1 fixed. Each data point in the graphs represents the mean value of $P V / C A P E X$ over 1000 draws. In particular, the figures represent variations in wind speeds, electricity price drifts, and discount rates.

(a) Changing Wind Speeds.

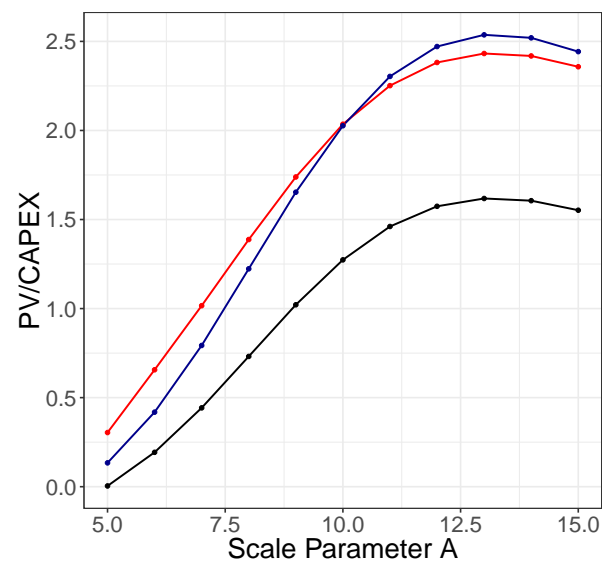

(c) Drift in Electricity Prices.

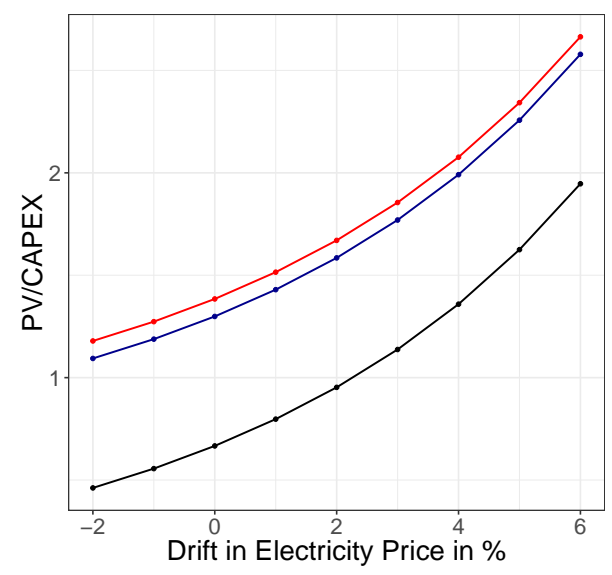

(e) Uncertainty in Subsidies.

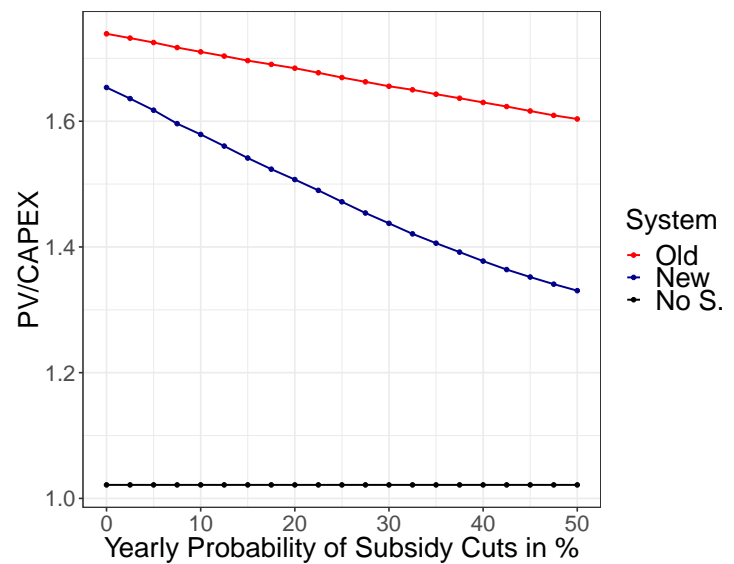

(b) Wind Speeds and Volatility.

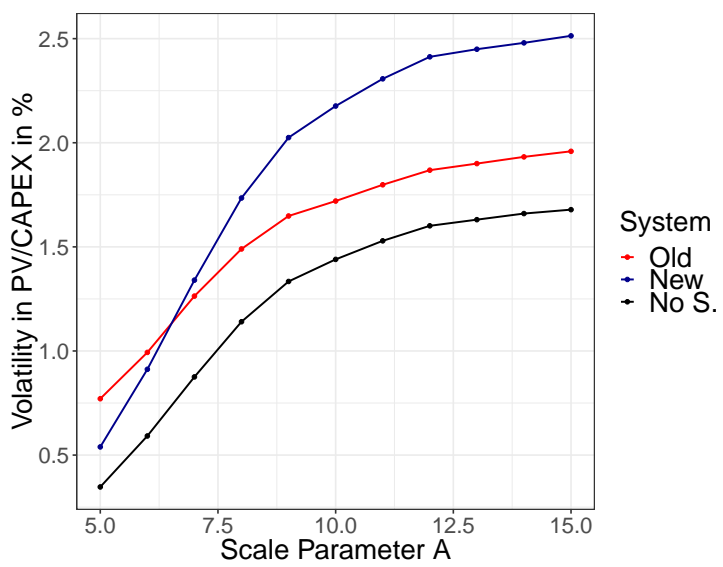

(d) Electricity Prices and Volatility.

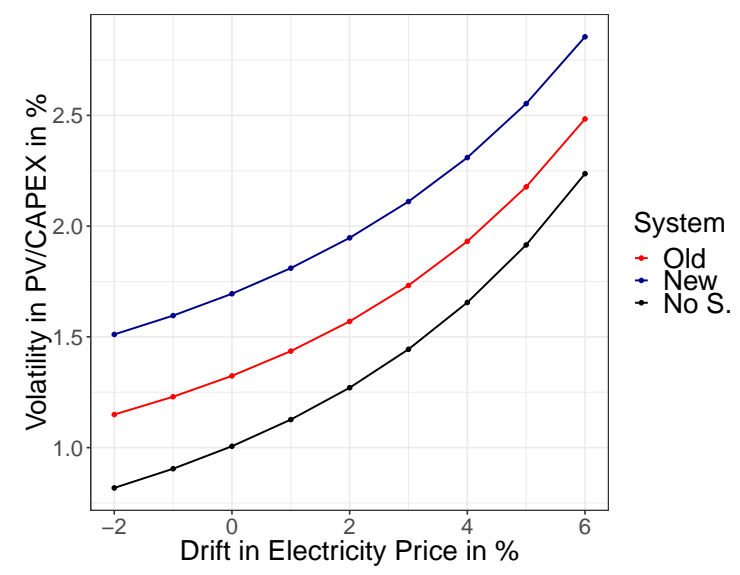

(f) Subsidy Defaults and Volatility.

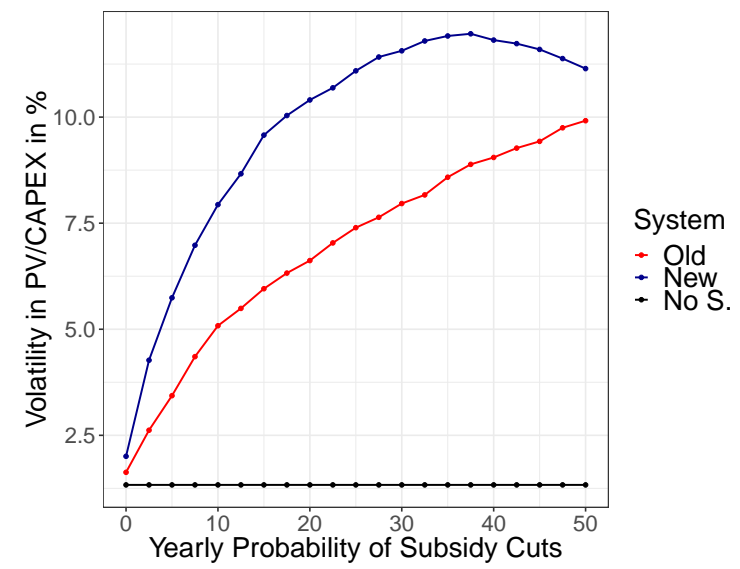

